\title{
Electronic structure regulation on layered double hydroxides for oxygen evolution reaction
}

\author{
Liangliang Huang a, Yuqin Zou a,*, Dawei Chen ab,,\#, Shuangyin Wang a,c,d,\$ \\ a State Key Laboratory of Chem/Bio-Sensing and Chemometrics, Provincial Hunan Key Laboratory for Graphene Materials and Devices, College of \\ Chemistry and Chemical Engineering, Hunan University, Changsha 410082, Hunan, China \\ b College of Materials Science and Engineering, Qingdao University of Science and Technology, Qingdao 266042, Shandong, China \\ c Key Laboratory of Optoelectronic Devices and Systems of Ministry of Education and Guangdong Province, Shenzhen University, Shenzhen 518060, \\ Guangdong, China \\ d Shenzhen Research Institute of Hunan University, Shenzhen 518057, Guangdong, China
}

\section{A R T I C L E I N F O}

\section{Article history:}

Received 5 January 2019

Accepted 13 February 2019

Published 5 December 2019

\section{Keywords:}

Oxygen evolution reactions

Layered double hydroxide

Cationic/Anionic regulation

Defect engineering

Electrocatalyst

Electron

Doping

\begin{abstract}
A B S T R A C T
Oxygen evolution reactions (OERs) as core components of energy conversion and storage technology systems, such as water splitting and rechargeable metal-air batteries, have attracted considerable attention in recent years. Transition metal compounds, particularly layered double hydroxides (LDHs), are considered as the most promising electrocatalysts owing to their unique two-dimensional layer structures and tunable components. However, heir poor intrinsic electrical conductivities and the limited number of active sites hinder their performances. The regulation of the electronic structure is an effective approach to improve the OER activity of LDHs, including cationic and anionic regulation, defect engineering, regulation of intercalated anions, and surface modifications. In this review, we summarize recent advances in the regulation of the electronic structures of LDHs used as electrocatalysts in OERs. In addition, we discuss the effects of each regulation type on OER activities. This review is expected to shed light on the development and design of effective OER electrocatalysts by summarizing various electronic structure regulation pathways and the effects on their catalytic performances.
\end{abstract}

(C) 2019, Dalian Institute of Chemical Physics, Chinese Academy of Sciences. Published by Elsevier B.V. All rights reserved.

\section{Introduction}

With the increasing depletion of traditional fossil energy sources and related environmental problems, the demand for clean and sustainable energy has increased rapidly [1-4]. Therefore, the development of renewable energy technology is considered as one of the most promising ways for the solution of these problems [5-8]. Among the various strategies, electrocatalytic water splitting constitutes an attractive strategy to produce hydrogen fuel, including the oxygen evolution reaction
(OER: $2 \mathrm{H}_{2} \mathrm{O} \rightarrow \mathrm{O}_{2}+4 \mathrm{H}^{+}+4 \mathrm{e}^{-}$) at the anode and hydrogen evolution reaction (HER) (HER: $2 \mathrm{H}^{+}+2 \mathrm{e}^{-} \rightarrow \mathrm{H}_{2}$ ) at the cathode [9-11]. HER is a two electron-transfer reaction with low-energy consumption (low overpotential) [12-14]. However, the OER is a sluggish, four electron-proton coupled kinetic reaction, with high-energy consumption (high overpotential) that limits the practical application of electrocatalytic water splitting [15-17]. OER is also the core reaction in metal-air batteries and fuel cells $[18,19]$. Their applications are hindered by the slow kinetics of OER $[20,21]$.

\footnotetext{
* Corresponding author. E-mail: yuqin_zou@hnu.edu.cn

\# Corresponding author. E-mail: daweichen@qust.edu.cn

\$Corresponding author. E-mail: shuangyinwang@hnu.edu.cn

DOI: S1872-2067(19)63284-5 | http://www.sciencedirect.com/science/journal/18722067 | Chin. J. Catal., Vol. 40, No. 12, December 2019
} 
Noble metal oxides $\left(\mathrm{RuO}_{2}\right.$ and $\left.\mathrm{IrO}_{2}\right)$ are regarded as the state-of-the-art OER catalysts with increased activities in acidic and alkaline media [22-24]. Nonetheless, their high costs, scarcity, and low stability, have restricted considerably their large-scale applications [25-27]. Therefore, designing low-cost and active catalysts is highly desirable. The earth-abundant, transition metal-based ( $\mathrm{Ni}, \mathrm{Co}, \mathrm{Mn}, \mathrm{Fe}$, etc.) materials, including oxides/hydroxides [28-31], chalcogenides [31-33], phosphides $[34,35]$, nitrides [36,37], and borates $[2,38]$, have been extensively investigated, and are expected to replace the noble, metal-based catalysts to promote the practical application of electrocatalytic water splitting.

Layered double hydroxides (LDHs) have been extensively studied as highly efficient OER electrocatalysts owing to their low cost and abundance $[39,40]$. Specifically, LDHs, a family of two-dimensional (2D) layered nanomaterials, consist of brucite-like layers with positively charged multimetal cations and interlayer compensating anions [41-43]. In general, most of the LDHs can be described as $\left[\mathrm{MII}_{1-x} \mathrm{MIII}_{x}(\mathrm{OH})_{2}\right]^{x+}\left(\mathrm{A}^{n-}\right)_{x / n} \cdot y \mathrm{H}_{2} \mathrm{O}$, in which MII are divalent metal ions (such as $\mathrm{Co}, \mathrm{Fe}, \mathrm{Ni}, \mathrm{Cu}, \mathrm{Zn}$, etc.), MIII are trivalent metal ions (such as $\mathrm{Ga}, \mathrm{Cr}, \mathrm{Fe}, \mathrm{Mn}, \mathrm{Co}, \mathrm{Al}$, etc.), where $x$ is in the range of 0.2 to 0.33 , and $\mathrm{A}^{n-}$ is the interlayer anion (such as $\mathrm{F}^{-}, \mathrm{SO}_{4}{ }^{2-}, \mathrm{CO}_{3}{ }^{2-}, \mathrm{NO}_{3}{ }^{-}$, and $\mathrm{ClO}_{4}{ }^{-}$) $[44,45]$. Compared to single metal hydroxides, mixed metal hydroxides with electron transfers and orbital transitions are considered to be beneficial to the enhancement of the catalytic activity toward the OER $[46,47]$. In particular, the interlayer balanced anions can be exchanged by other organic and inorganic anions $[48,49]$. Furthermore, LDHs have been extensively applied in various fields owing to their unique, 2D layered structure, easily tailored properties, and versatility of chemical compositions $[50,51]$. However, the limited number of active sites and the inferior intrinsic activity of the catalytic sites have hindered the development of LDHs as high-performance OER catalysts $[52,53]$.

Numerous strategies have been developed to solve the aforementioned problems. An effective approach is the exfoliation of the structures of bulk LDHs into 2D ultrathin structures to increase the number of active sites $[40,54]$. The 2D ultrathin structure has high-specific surface area, abundant active sites, fast charge transfer rate, and convenient diffusion pathways that are conducive to the enhancement of catalytic performance [55]. For instance, Huang et al. [56] reported an ultrathin cobalt oxyhydroxide $(\gamma-\mathrm{CoOOH})$ nanosheet as an efficient OER electrocatalyst. The as-synthesized ultrathin $\gamma$-CoOOH nanosheet associated with the unsaturated coordination of the $\mathrm{CoO}_{6-x}$ sites can optimize the electronic structure of the material and facilitate the electron transfer and conversion [56]. Thus, this compound exhibited high-catalytic activity toward the OER compared to the bulk counterpart and the state-of-the-art $\mathrm{IrO}_{2}$ electrocatalyst.

In addition, the regulation of the electronic structure is another effective approach and has been extensively studied because it can increase the intrinsic activity of the active sites, thus promoting the enhancement of the electrocatalytic performance of the catalysts $[46,57]$. In particular, the electronic structure regulation could modify the intrinsic activity of the active site by changing the lattice and bond length of the crystal $[7,58]$. Some results showed that the optimal adsorption capability of oxygenated intermediates toward higher electrocatalytic activity could be obtained by tuning the electronic structure of the catalysts $[56,57]$. Furthermore, the regulation of the electronic structure is usually accompanied by the electron transfer and the improvement of the electrical conductivity within the material [14]. Specifically, the electronic regulation can be achieved by optimizing the composition, tailoring the coordination states, tuning defects/phase/interface, and doping heteroatoms $[59,60]$. For instance, suitable oxygen vacancies existing in transition metal oxides/hydroxides could assist the adsorption of oxygen-containing species and promote their catalytic performances [61,62]. Accordingly, metal vacancies could allow various electron and orbital distributions to increase the valence state of nearby metal sites and promote the activity of OERs [57,63].

Compared to other transition metal compounds, the LDH electrocatalysts exhibited superior OER activity owing to their unique electronic, 2D layered structures, easily tailored properties, and versatility of chemical compositions. Therefore, LDHs constitute typical electrocatalysts in the study of the regulation of electronic structures on catalytic performance. However, there are a few reviews that study the effect of electronic structure regulation on LDHs for promoting their OER catalytic performance. In this review, we focus on recent progress in the electronic structure regulation of LDHs in promoting water oxidation. Various types of electronic structure regulations on LDH electrocatalysts are also introduced. Specifically, the electronic structure regulation includes cationic regulation, anionic regulation, defect engineering, regulation of intercalated anions, and surface modifications. In addition, we focus on the effects of electronic structure regulation on the OER activity. Finally, the challenges and outlook of LDHs are also presented. This review will provide some knowledge for the development and design of superior OER catalysts based on the regulation of the electronic structure.

\section{Cationic regulation}

The OER process could be expressed according to the following elementary steps [64-66]. In alkaline conditions,

$$
\begin{gathered}
4 \mathrm{OH}^{-} \rightarrow \mathrm{OH}^{*}+3 \mathrm{OH}^{-}+\mathrm{e}^{-} \\
\mathrm{OH}^{*}+3 \mathrm{OH}^{-} \rightarrow \mathrm{O}^{*}+2 \mathrm{OH}^{-}+\mathrm{H}_{2} \mathrm{O}+\mathrm{e}^{-} \\
\mathrm{O}^{*}+2 \mathrm{OH}^{-}+\mathrm{H}_{2} \mathrm{O} \rightarrow \mathrm{OOH}^{*}+\mathrm{OH}^{-}+\mathrm{H}_{2} \mathrm{O}+\mathrm{e}^{-} \\
\mathrm{OOH}^{*}+\mathrm{OH}^{-}+\mathrm{H}_{2} \mathrm{O} \rightarrow \mathrm{O}_{2}+2 \mathrm{H}_{2} \mathrm{O}+\mathrm{e}^{-} \\
\text {In acidic conditions, } \\
2 \mathrm{H}_{2} \mathrm{O} \rightarrow \mathrm{OH}^{*}+\mathrm{H}_{2} \mathrm{O}+\mathrm{H}^{+}+\mathrm{e}^{-} \\
\mathrm{OH}^{*}+\mathrm{H}_{2} \mathrm{O} \rightarrow \mathrm{O}^{*}+\mathrm{H}_{2} \mathrm{O}+\mathrm{H}^{+}+\mathrm{e}^{-} \\
\mathrm{O}^{*}+\mathrm{H}_{2} \mathrm{O} \rightarrow \mathrm{OOH}^{*}+\mathrm{H}^{+}+\mathrm{e}^{-} \\
\mathrm{OOH}^{*} \rightarrow \mathrm{O}_{2}+\mathrm{H}^{+}+\mathrm{e}^{-}
\end{gathered}
$$

The OER process involves ${ }^{*} \mathrm{OH},{ }^{*} \mathrm{O}$, and ${ }^{*} \mathrm{OOH}$ intermediates that are absorbed and desorbed on the surfaces. The OER activity is poor when the adsorption energy of the intermediates is too strong or too weak $[67,68]$. The performance of the catalyst is optimal when the adsorption and desorption energies are close to zero $[64,69]$. Previous studies revealed that the intro- 
duction of a second or third metal cation in materials could optimize the adsorption energy of the active sites [68]. For instance, FeCo oxyhydroxides have been extensively studied as OER catalysts. Zhang et al. incorporated W6+ into FeCo oxyhydroxides to optimize the adsorption energy of the intermediate, thus leading to an obvious improvement in the OER activity [68]. Conversely, the introduction of the high oxidation state of tungsten (W) could a) alter the local coordination environment of the catalysts, b) tune its local coordination environment, and c) optimize the consequent energetics of the OER. Additionally, density functional theory plus $U(D F T+U)$ calculations revealed that high-valence tungsten could change the geometric and electronic structures surrounding metal sites, thus providing the near-optimal energetics for the OER intermediates and an optimal catalytic performance [68]. Therefore, it is found that the introduction of a second or third metal can provide additional active sites, cause lattice defects, distortion, and promote electron interactions [71,72]. Moreover, the electronic structure of the catalyst plays an important role in the determination of the adsorption energy of the intermediate [59,72,73]. It is well known that cationic/anionic regulation can effectively regulate the electronic structure of catalysts $[74,75]$. According to the previous literature, cationic regulation has been demonstrated as an effective approach for tuning the local coordination environment and for fabricating the defect of the catalyst to expose more active sites and optimize its adsorption states and charge transfer properties $[59,76]$.

\subsection{Single-valence metal cation regulation}

Cationic regulation can be achieved by doping, etching, or replacing other cations [77]. Recently, many single-valence metal cations have been studied as the doping elements for LDHs, including Co, Zn, Al, Ir, and others.

Density functional theory (DFT) calculations revealed that the Co incorporation of LDHs can effectively modify the energetics of the OER reaction intermediates and decrease its overpotential to improve its electrocatalytic performance [78]. In 2015, Long et al. [78] synthesized an LDH which incorporated a tri-metal $(\mathrm{Fe}, \mathrm{Ni}$, and $\mathrm{Co})$ by controlling the ratio of the trivalent ion as an advanced electrocatalyst. The thicknesses of the LDHs decrease with the increase of the Co content. The as-synthesized ultrathin FeNiCo LDHs showed the enhanced OER activity, increased the number of the active sites, and improved the conductivity of catalysts, which was ascribed to the modulated electronic structures of catalytic centers by the incorporation of Co. Two years later, Thenuwara et al. [79] reported the highly efficient electrocatalytic activity of NiFe LDHs based on the Co incorporation using substitution or intercalation. X-ray diffraction (XRD) patterns showed that the interlayer spacing of the NiFe LDH with the intercalated $\mathrm{Co}^{2+}$ increased, while that of the NiFe LDH with the substituted Co did not change (Fig. 1(A)). The X-ray absorption near edge structure (XANES) spectra indicated that the NiFe LDH sample with the substituted Co had a higher proportion of $\mathrm{Co}^{3+}$ than the intercalated ones (Fig. 1(B)). As shown in Fig. 1(C), the NiFe LDH with the intercalated Co exhibited an optimal OER catalytic performance with an overpotential equal to $265 \mathrm{mV}$ at $10 \mathrm{~mA}$ $\mathrm{cm}^{-2}$ owing to the synergistic effects among the interlayer water and active cobalt sites. Additionally, the NiFe LDH with the substituted Co led to an obviously enhanced performance compared to pristine NiFe LDH. The DFT calculation (Fig. 1(D)) shows that the hybridization of the Co $3 d$ state with the $02 p$ state modified the state density near the maximum of the valence band to effectively change the energetics of the OER reaction intermediates of $0^{*}$, thus resulting in a significantly increased OER activity.

Furthermore, zinc $(\mathrm{Zn})$ regulations of LDHs have also been studied. Foruzin et al. [80] synthesized the ternary-component nickel-zinc-iron layered double hydroxides $\left(\mathrm{Ni}_{x} \mathrm{Zn}_{y} \mathrm{Fe}_{z}\right.$-LDHs) by the co-precipitation method. In this case, physical characterizations (using scanning electron microscopy (SEM), XRD, and diffuse reflectance spectroscopy) showed that the $\mathrm{Ni}_{2} \mathrm{Zn}_{0.5} \mathrm{Fe}-\mathrm{LDH}$ had the highest crystallinity and the lowest gap band energy than other ternary LDH components, binary LDH components, $\mathrm{Ni}_{2} \mathrm{Fe}-\mathrm{LDH}$, and ZnFe-LDH. Therefore, high-electrical conductivity of $\mathrm{Ni}_{2} \mathrm{Zn}_{0.5} \mathrm{Fe}-\mathrm{LDH}$ was achieved by the incorporation of $\mathrm{Zn}$ to regulate the electronic structure. Thus, the $\mathrm{Ni}_{2} \mathrm{Zn}_{0.5} \mathrm{Fe}-\mathrm{LDH}$ with modified carbon paste electrodes showed outstanding OER catalytic performances with a low-onset potential, small Tafel slope compared to other samples, and outstanding structural stability.

Furthermore, based on the literature, the introduction of trivalent aluminum (Al) ions will greatly increase the fraction of low-coordination active sites in LDHs [81]. Correspondingly, the etching of $\mathrm{Al}$ is beneficial in creating metal vacancies [81]. Thus, Al ions were usually used to regulate the surface electronic configurations of LDHs. For example, the ultrathin $\mathrm{Ni}_{3} \mathrm{FeAl}_{x}$ trinary LDH nanosheets were reported by Jin's group [81]. In this work, the ultrathin $\mathrm{Ni}_{3} \mathrm{FeAl}_{x}$ trinary $\mathrm{LDH}$ nanosheets were obtained by the substitution and the etching of Al species, as illustrated in Fig. 2(A). The acquired transmission electron microscopy (TEM) images indicated that the morphology of the $\mathrm{Ni}_{3} \mathrm{FeAl}_{x}$-LDH nanosheets become rough and with low crystallinity following the increase of their aluminum content (Fig. 2(B)). The XRD results confirmed that the Al substitution increased the structural disorder and decreased the crystallization degree of the $\mathrm{Ni}_{3} \mathrm{FeAl}_{x}$-LDH sample (Fig. 2(C)). The X-ray photoelectron spectroscopy (XPS) characterization suggested that the concentration of $\mathrm{Ni}^{3+}$ in $\mathrm{Ni}_{3} \mathrm{FeAl}_{0.91}-\mathrm{LDH}$ increases when the atomic ratio of $\mathrm{Al}^{3+}$ increases (Fig. 2(D)). The electrocatalytic activity of $\mathrm{Ni}_{3} \mathrm{FeAl}_{x}-\mathrm{LDHs}$ is also evaluated (Fig. 2(E)). The $\mathrm{Ni}_{3} \mathrm{FeAl}_{0.91}-\mathrm{LDH}$ nanosheets yield the highest catalytic performance in OERs with a low-overpotential (350 $\mathrm{mV}$ ) at a current density of $13.2 \mathrm{~mA} \mathrm{~cm}^{-2}$ compared to the nanosheets of $\mathrm{Ni}_{3} \mathrm{Fe}-\mathrm{LDH}, \mathrm{Ni}_{3} \mathrm{FeAl}_{1.27}-\mathrm{LDH}$, and $\mathrm{Ni}_{3} \mathrm{FeAl}_{2.73}-\mathrm{LDH}$. Furthermore, the nanosheets of $\mathrm{Ni}_{3} \mathrm{FeAl}_{x}-\mathrm{LDH}$ exhibited high long-term durability and electrochemical stability in alkaline solutions. The ultrahigh activity was attributed to the increased content of active sites of $\mathrm{Ni}^{3+}$ on the catalyst surface owing to the use of the appropriate ratio of $\mathrm{Al}^{3+}$. Additionally, the partial etching/dissolution of $\mathrm{Al}^{3+}$ in a strong alkaline solution would create more defect sites in the $\mathrm{N}_{3} \mathrm{FeAl}_{\mathrm{x}}-\mathrm{LDH}$ lattices to increase the electrochemically active surface area and expose more $\mathrm{Ni}$ 

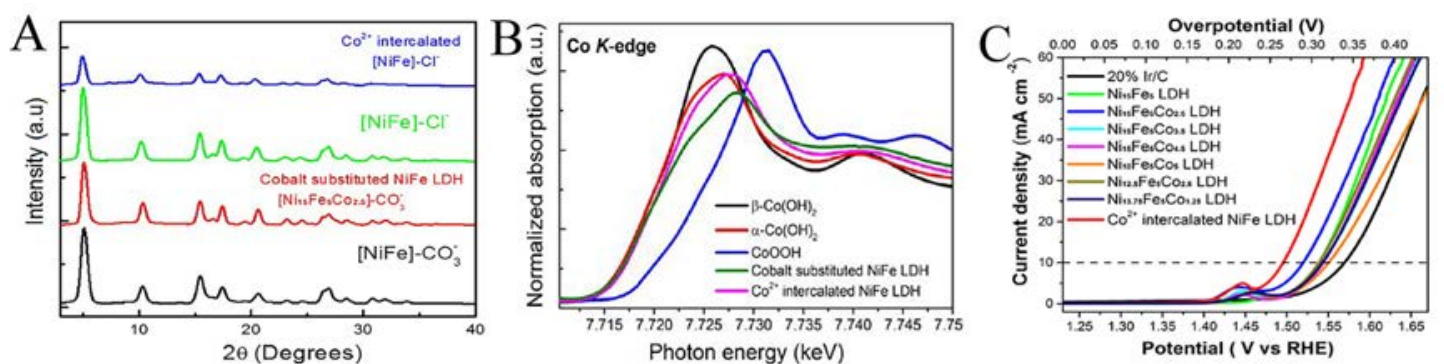

$\mathrm{D}(\mathrm{a})$
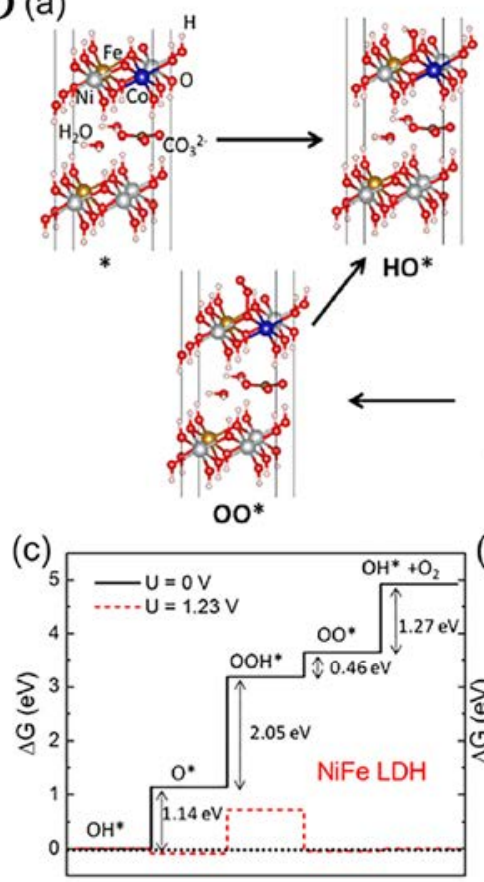

Reaction coordinate

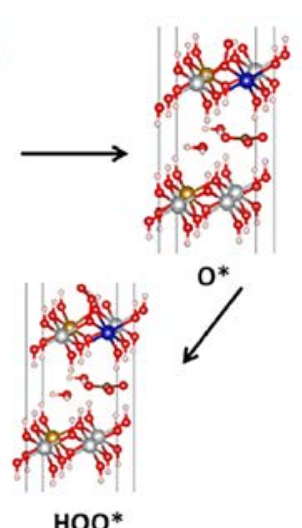

(d) (b)

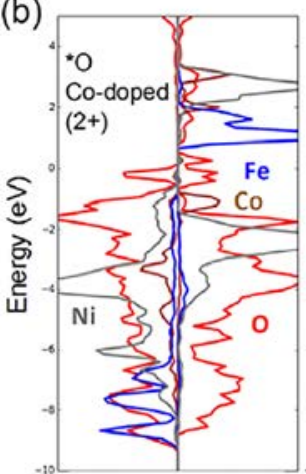

Density of states

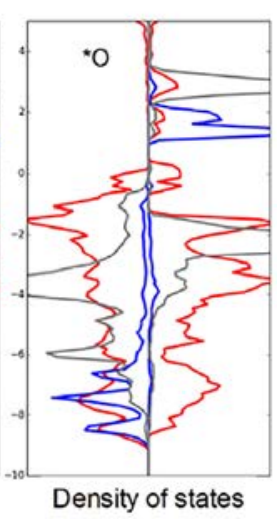

(e)

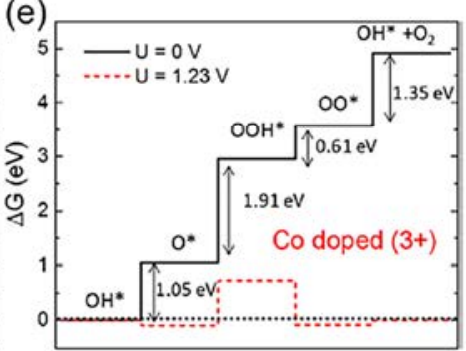

Reaction coordinate

Fig. 1. (A) XRD data of pristine NiFe $\mathrm{LDH}$ with different interlayer anions $\left(\mathrm{CO}_{3}{ }^{2-}\right.$ and $\left.\mathrm{Cl}^{-}\right)$, NiFe substituted with Co, and NiFe $\mathrm{LDH}$ intercalated with $\mathrm{Co}^{2+}$. (B) Normalized Co-K edge spectra of NiFe LDH modified with Co with standards. (C) Polarization curves of modified NiFe LDH (intercalated and substituted) with Co, pristine NiFe LDH, and 20\% iridium carbon. (D) (a) Relaxed structures of initial and intermediate states, (b) projected density of states of oxygen absorbed NiFe LDH $\left({ }^{*} 0\right)$ with and without $\mathrm{Co}^{2+}$ doping in the metal hydroxide nanosheet. Standard free energy diagrams for the OER at zero potential $(\mathrm{U}=0)$ and equilibrium potential for oxygen evolution $(\mathrm{U}=1.23)$ for $(\mathrm{c}) \mathrm{NiFe} \mathrm{LDH}(\mathrm{d}) \mathrm{Co}^{2+}$-doped, and $(\mathrm{e}) \mathrm{Co}^{3+}$ doped systems [79]. Reprinted with permission from [79].

and Fe active sites, thus leading to the enhancement of the OER catalytic activity.

Ir4+-doped NiFe LDH (NiFeIr LDH) was synthesized by a facile hydrothermal method using urea as a precipitant [82]. The NiFeIr LDH compound showed a nanosheet structure with a uniform distribution of $\mathrm{Ni}, \mathrm{Fe}$, Ir, and $\mathrm{O}$. The XPS results confirmed that the valence state of the Ir was +4 . The NiFeIr LDH compound exhibited a superior OER activity after the $\mathrm{Ir}^{4+}$ doping with a low overpotential of $200 \mathrm{mV}$ at $10 \mathrm{~mA} \mathrm{~cm}^{-2}$. Additionally, the NiFeIr LDH had a Pt-like HER performance with an overpotential of $34 \mathrm{mV}$ at $10 \mathrm{~mA} \mathrm{~cm}^{-2}$. The excellent electrocatalytic performance of NiFeIr LDH was ascribed to the fact that $\mathrm{Ir}^{4+}$ doping promoted the water dissociation process (Volmer step) and regulated the electronic structure.

\subsection{Multivalence metal cation regulation}

In addition to single-valence metal cations, the multivalence metal cations, such as $\mathrm{Fe}, \mathrm{Cr}, \mathrm{Ce}, \mathrm{V}, \mathrm{Mn}$, have been extensively investigated. Studies have shown that compared to single-valence metal cations, the introduction of mutivalence metal cations can not only regulate the electronic structure of LDHs but also affect the water dissociation process [71,83]. For example, previous results have shown that the introduction of iron (Fe) into the structure could increase the conductivity and create more active sites owing to the fabrication of crystal structural distortion, thus leading to an enhanced OER performance in the case of the catalyst $[84,85]$. More recently, Wang et al. [86] introduced the NiCoFe LDH nanosheet arrays via the exchange of cations of $\mathrm{Co}, \mathrm{Ni}$, and $\mathrm{Fe}$, in the modified carbon fiber cloth of NiCo-LDH (NiCoFe-LDH/CFC) at room temperature. After the cation exchange reaction $(1 \mathrm{~h})$, the NiCoFe-LDH/CFC could maintain the original nanosheet structure, while the incorporation of Fe could cause a slight crystal structure disorder. After the introduction of $\mathrm{Fe}$, the NiCoFe-LDH/CFC exhibited an enhanced OER activity compared to 

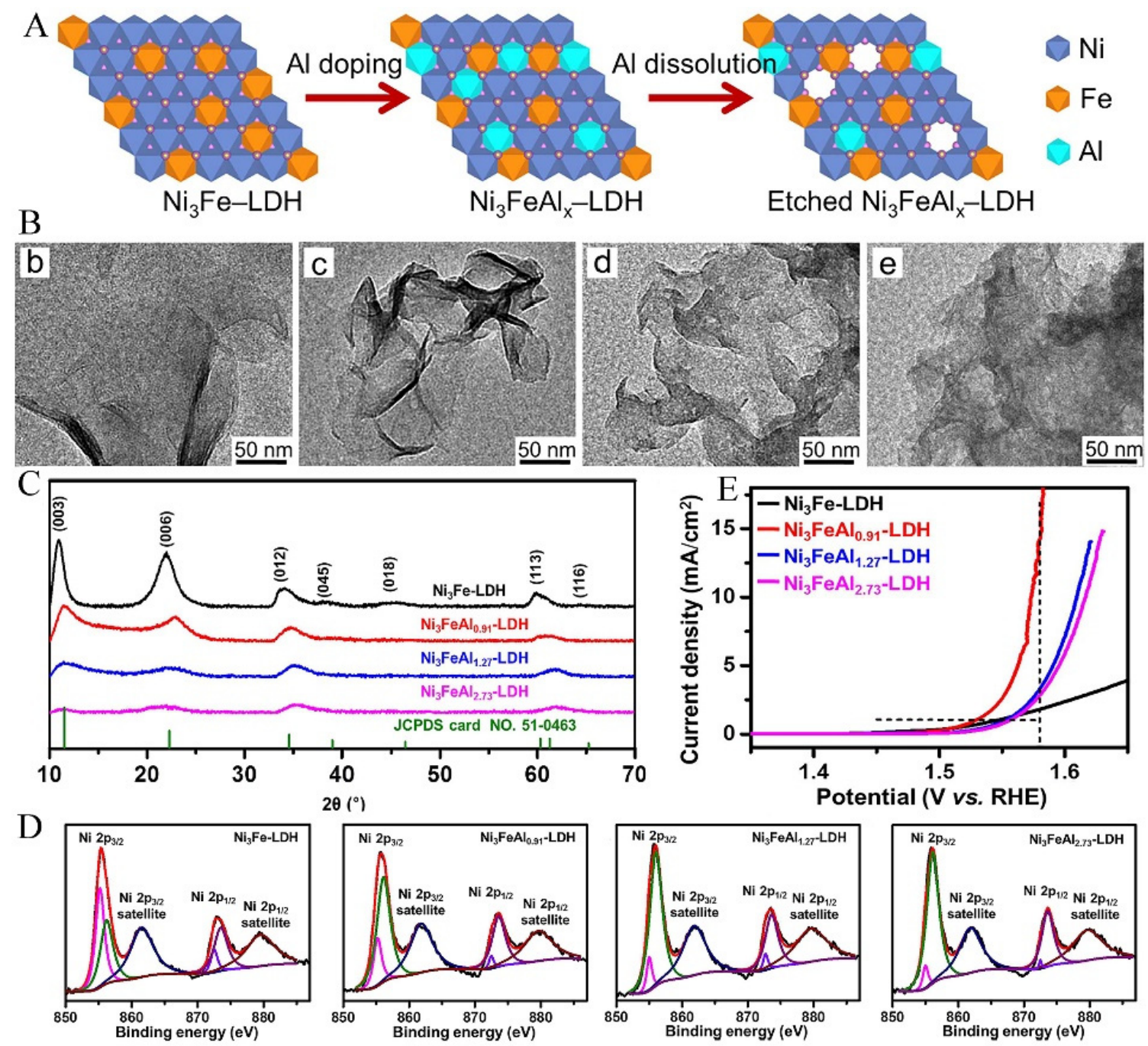

Fig. 2. (A) Schematic representation of the preparation process of $\mathrm{Ni}_{3} \mathrm{FeAl}_{x}-\mathrm{LDH}$ nanosheets; (B) TEM images of (b) $\mathrm{Ni}_{3} \mathrm{Fe}-\mathrm{LDH}$, (c) $\mathrm{Ni}_{3} \mathrm{FeAl} \mathrm{O}_{0.9}-\mathrm{LDH}$, (d) $\mathrm{Ni}_{3} \mathrm{FeAl}_{1.27}-\mathrm{LDH}$, and (e) $\mathrm{Ni}_{3} \mathrm{FeAl}_{2.73}-\mathrm{LDH}$; (C) XRD spectra of $\mathrm{Ni}_{3} \mathrm{FeAl}_{x}-\mathrm{LDH}$ nanosheets $(x=0,0.91,1.27$, and 2.73); (D) XPS spectra at the $2 p$ region of $\mathrm{Ni}$ of the $\mathrm{Ni}_{3} \mathrm{FeAl}_{x}$-LDH nanosheets $\left(x=0,0.91,1.27\right.$, and 2.73, respectively); (E) the iR-corrected OER polarization curves of $\mathrm{Ni}_{3} \mathrm{FeAl} x_{x}-\mathrm{LDH}$ nanosheets recorded at a scan rate of $10 \mathrm{mV} \mathrm{s}^{-1}$ in $1.0 \mathrm{~mol} / \mathrm{L} \mathrm{KOH} \mathrm{[81].} \mathrm{Reprinted} \mathrm{with} \mathrm{permission} \mathrm{from} \mathrm{[81].}$

pristine NiCo-LDH. The significantly improved OER activity of $\mathrm{NiCoFe-LDH/CFC} \mathrm{was} \mathrm{ascribed} \mathrm{to} \mathrm{the} \mathrm{incorporation} \mathrm{of} \mathrm{Fe} \mathrm{that}$ led to the exposure of more active sites by building disorders in the crystal structure and by reducing the thickness of the nanosheets. Furthermore, the incorporation of Fe could increase the conductivity of the material and enhance the intrinsic electrocatalytic activity of the catalyst [86].

Moreover, it has been reported that the introduction of chromium (Cr) cations into LDH structures can buffer the multi-electron process necessary for the OER because the Cr metal has several oxidation states (from +1 to +6 ) [83]. Accordingly, addition of $\mathrm{Cr}$ introduces additional active sites [83]. Jin et al. [83] reported the existence of tri-metallic NiFeCr LDH within the unique 2D structure as the OER electrocatalyst. After the introduction of $\mathrm{Cr}$, the crystal structure of NiFeCr $\mathrm{LDH}$ remained unchanged. After the additional $\mathrm{F}^{-}$ions, the crystallinity and nanostructure morphology of NiFeCr-F LDH was improved. Correspondingly, the oxidation state of $\mathrm{Cr}$ was confirmed to be +3. X-band electron paramagnetic resonance spectroscopy
(EPR) results suggested that the incorporation of $\mathrm{Cr}$ could regulate the electronic structure of NiFe-based LDH. The NiFeCr-6:2:1 sample yielded the best OER activity with favorable kinetics and higher electrochemically active surface areas (ECSA) compared to the NiCr, NiFe, and NiFeCr LDH materials. The high catalytic activity of NiFeCr LDH was attributed to the following characteristics: (1) the modular 2D layered structure that facilitated charge transport, (2) the incorporation of multivalent $\mathrm{Cr}$ that tuned the electronic structure of LDHs and buffered the multielectron process necessary for OER, and (3) the strongly synergistic interactions among $\mathrm{Ni}, \mathrm{Fe}$, and $\mathrm{Cr}$.

As commonly known, cerium (Ce) has a flexible coordination number [71]. When Ce is introduced into the structure of LDH, it will cause lattice defects and promote the interaction between active sites, thus modifying the electrocatalyst properties of the catalyst [71]. Xu et al. [71] prepared Ce-doped NiFe-LDH nanosheets/carbon nanotubes (denoted as $\mathrm{Ni}$ FeCe-LDH/CNT) by a facile and low-cost in situ self-assembly strategy as the electrocatalyst for OER. In this case, it was found 
that NiFeCe-LDH nanosheets were uniformly distributed on carbon nanotubes (CNT). CNT combined with the LDH-based catalyst could enhance the electrical conductivity and improve the specific surface area and the number of active sites. Given that the ionic radius of $\mathrm{Ce}^{3+}(102 \mathrm{pm})$ was much larger than that of $\mathrm{Fe}^{3+}(55 \mathrm{pm})$, isomorphic substitution of $\mathrm{Fe}^{3+}$ by $\mathrm{Ce}^{3+}$ resulted in lattice defects. Therefore, the introduction of a high, flexible coordination number of $\mathrm{Ce}^{3+}$ into the NiFe-LDH structure could increase the interlayer spacing and promote the formation of rich oxygen vacancies. These defects are more conducive to the exposure of more active sites and to the enhancement of the coupling with CNT. Thus, $5.0 \%$ Ce-NiFe-LDH/CNT led to a highly efficient OER activity with a lower overpotential of $227 \mathrm{mV}$ as well as delivered a current

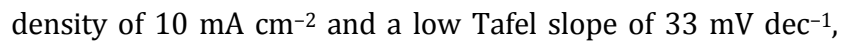
which were better than those exhibited by the counterpart and the most reported NiFe-based electrocatalysts.

Vanadium (V) has been extensively studied owing to its low price, series of valence states, and potential catalytic activity $[87,88]$. V-doped NiFe LDH nanosheet arrays on Ni foam were prepared by a one-step hydrothermal method [87]. V-doping did not change the layered structures of NiFe LDHs, and thus maintained their crystal structures. The XPS analysis indicated that the $\mathrm{V}$ element in the $\mathrm{NiFeV}$ LDHs existed in the $+3,+4$, and +5 oxidation states, owing to the fact that $\mathrm{V}^{3+}$ was partially oxidized by oxygen to the $\mathrm{V}^{4+}$ and $\mathrm{V}^{5+}$ states during the synthesizes of LDHs. As a result, the NiFeV LDHs exhibited superior OER performances with a lower overpotential of $195 \mathrm{mV}$ at a current density of $20 \mathrm{~mA} \mathrm{~cm}-2$, and a Tafel slope of $42 \mathrm{mV} \mathrm{dec}^{-1}$ compared to the commercial $\mathrm{RuO}_{2}$, NiV LDHs, and NiFe LDHs. In addition, the $\mathrm{NiFeV} \mathrm{LDHs} \mathrm{exhibited} \mathrm{a} \mathrm{favorable} \mathrm{OER} \mathrm{kinetics}$ response with a higher turnover frequency (TOF) value $(0.04$ $\mathrm{s}^{-1}$ ) and more electrochemical active sites with larger $C_{d l}$ values (6483 $\mathrm{uF} \mathrm{cm}^{-2}$ ). DFT calculations demonstrated that doping of $\mathrm{V}$ in NiFe LDHs could narrow the bandgap to improve the electrical conductivity of the material [87]. Therefore, the NiFeV LDHs nanosheets showed an outstanding OER activity owing to the enhanced electrical conductivity and increased number of active sites as well as promoted electron transfer caused by the modulation of the electronic structure and the narrowing of the bandgap.

The DFT results showed that the $\mathrm{Mn}^{4+}$ doping of LDH could narrow the bandgap between the valence and conduction and improve the electrical conductivity [89]. Lu et al. [89] reported $\mathrm{Mn}^{4+}$ doped NiFe LDHs (denoted as NiFeMn LDHs) through a simple co-precipitation method. The NiFeMn-LDH has a flower-like nanoplate structure, and an average size and thickness of $\sim 50 \mathrm{~nm}$ and $\sim 3.7 \mathrm{~nm}$, respectively. The crystal structure of the LDHs remained unchanged, which indicated that the Mn doping did not cause any structural deformation. The XPS results demonstrated that the Mn in the NiFeMn-LDH oxidation states was +4. The NiFeMn-LDH exhibited excellent OER activity with a low-onset potential of $1.43 \mathrm{~V}$, fast increasing OER current, low-Tafel slope, and a high-TOF value, which were superior to those for NiFe-LDH and NiMn-LDH. In addition to the high-catalytic activity toward OER, the ternary $\mathrm{NiFeMn-LDH} \mathrm{catalyst} \mathrm{yielded} \mathrm{significant} \mathrm{durability} \mathrm{in} \mathrm{alkaline}$ solutions. The author attributed the high OER activity of the NiFeMn-LDH to the $\mathrm{Mn}^{4+}$ doping into the layered structure, which caused a tunable electronic structure, and higher electronical catalyst conductivity.

\section{Anionic regulation}

In addition to the cationic and anionic regulations as additional, effective approaches used to tune the electronic structure, the increase of the conductivity and optimization of the chemical adsorption to promote the interaction with reactants has been attracting increased attention [58,90,91]. Specifically, the metal cations of LDH-based catalysts are the actual active sites of the OER, and are conducive to the absorption of hydrogen but do not facilitate the desorption of oxygen [77,91]. Appropriately polarized anions can optimize the electronic structure of active sites by adjusting the ionic-covalency properties of the material to facilitate reactant adsorption, electron transfer, and product desorption, thus greatly enhancing their OER catalytic activities [92,93]. For instance, Shi and co-workers [94] reported the N-doped $\mathrm{CoS}_{2}$ as the OER electrocatalyst. In this case, the as-prepared $\mathrm{N}$-doped $\mathrm{CoS}_{2}$ exhibited a low overpotential of $240 \mathrm{mV}$ at $10 \mathrm{~mA} \mathrm{~cm}^{-2}$ and a high durability in the alkaline electrolyte. The DFT calculations suggested that $\mathrm{N}$ doping could adjust the valence state of the adjacent Co atoms and minimize the adsorption free energy of intermediates, which reduced the reaction barriers, and thus exhibited increased activities for OER [94]. In short, anionic regulation has been proven to be an effective way to tune the electronic properties and increase reactive sites [59]. Similarly, the electronic structure of the LDH-based catalyst is regulated by doping, etching, or the substitution of anions.

\subsection{Sulfur}

Oxygen and sulfur belong to the same group in the periodic table. Moreover, $\mathrm{O}^{2-}$ is a hard base which is difficult to polarize, while $\mathrm{S}^{2-}$ is a soft base, and is easily polarized in compounds $[93,95]$. When polarized $\mathrm{S}^{2-}$ partially substitutes $\mathrm{O}^{2-}$, it weakens the metal bond strength to promote oxygen desorption [47]. Recently, anionic regulated NiFe oxysulfide for oxygen electrocatalysis was reported by Zhang's group [93]. In this study, authors revealed that the optimized electronic structure achieved by regulating the ratio of $\mathrm{O}^{2-}$ and $\mathrm{S}^{2-}$, can facilitate the adsorption of reactants, electron transfer, and product desorption, and can thus greatly improve the OER catalytic performance. The S-doped NiFe LDH, which was named as NiFeS- $x(x$ is the mass ratio of TAA:NiFe LDH), could be achieved by the sulfurization of NiFe LDH precursors using thioacetamide (TAA) as the sulfurization reagent. NiFeS- $x$ exhibited the morphology of nanoparticles on the 3D graphene framework (GF) surface (Fig. 3(A)). The XPS and energy dispersive spectroscopy (EDS) analyses confirmed that the sulfur gradually substituted the original oxygen to form anionic regulated electrocatalysts (Fig. 3(B)). As a result, the NiFeS-2 electrocatalyst possessed an optimized catalytic activity with a low overpotential of $286 \mathrm{mV}$ at $10 \mathrm{~mA} \mathrm{~cm}^{-2}$ and the fastest kinetics (Fig. 3(C)). 

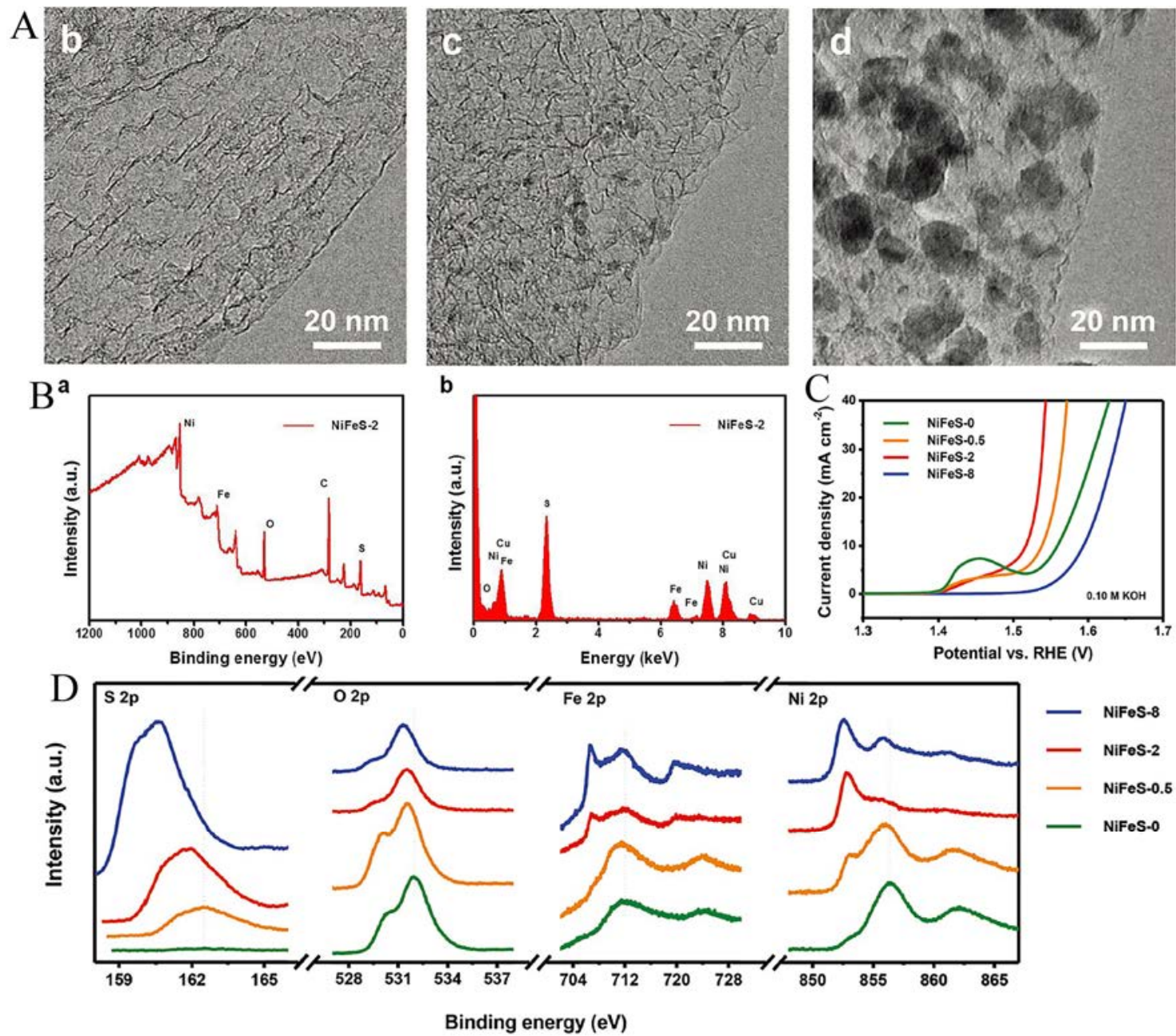

Fig. 3. (A) TEM images of (b) GF, (c) NiFe LDH, and (d) NiFeS-2. (B) Elemental composition analysis of the NiFeS-2 electrocatalyst, (a) XPS survey spectrum and (b) EDS pattern of the NiFeS-2 electrocatalyst. (C) 95\% iR-compensated LSV profiles of the NiFeS- $x$ electrocatalysts at a scan rate of $10.0 \mathrm{mV} \mathrm{s}^{-1}$ in $\mathrm{O}_{2}$ saturated $0.10 \mathrm{~mol} / \mathrm{L} \mathrm{KOH}$. (D) High-resolution S $2 p, 02 p$, Fe $2 p$, and Ni $2 p$ XPS spectra of NiFeS- $x$ electrocatalysts [93]. Reprinted with permission from [93]

With the increased content of sulfur, the high-resolution XPS spectra of $02 p$ and S $2 p$ shift to a lower binding energy, while the Fe $2 p$ and Ni $2 p$ shift to a lower binding energy (Fig. 3(D)). This result suggests that the polarized sulfur anions tend to give their dispersive electrons to adjacent metal ions. When sulfur and oxygen reach a certain proportion, NiFeS- $x$ possesses the optimal electronic structure and exhibits a superior catalytic performance in OERs.

Zhang's group [96] was the first to propose a method to synthesize hydroxysulfides using a room temperature sulfurization methodology. The CoAl layered double hydroxide (denoted as CoAl-OH) precursors were immersed in a high concentration of $\mathrm{S}^{2-}$ to form hydroxysulfides based on the continuous replacement of $\mathrm{OH}^{-}$by $\mathrm{S}^{2-}$. The anion-regulated $\mathrm{CoAl}$ hydroxysulfide $\left(\mathrm{Co}_{5} \mathrm{AlS}_{1.5}(\mathrm{OH})_{10}\right)$ exhibited excellent electrocatalytic performances toward the OER compared to pristine CoAl-OH. At the same time, the graphene-supported CoFe hydroxide nanoparticles ( $\mathrm{CoFe}-\mathrm{OH})$ were treated similarly. After the treatment, the $\mathrm{CoFeS}_{1.6}(\mathrm{OH})_{1.8}$ - $\mathrm{HT}$ showed an outstanding OER activity.

Recently, Wang's group [46] synthesized S2- regulated CoAl
LDHs with an $\mathrm{Al}^{3+}$ defect (denoted as PS-CoAl LDHs) using a modified water DBD plasma treatment in the $\mathrm{Na}_{2} \mathrm{~S}$ solution. In this case, the DBD plasma treatment could achieve a rapid and highly efficient transformation from $\mathrm{OH}^{-} / \mathrm{O}^{2-}$ to $\mathrm{S}^{2-}$ and induce the generation of metal defects. $\mathrm{Al}^{3+}$ defects could expose more active sites and the $\mathrm{S}^{2-}$ regulation could significantly improve the intrinsic conductivity as well as optimize the electronic structure of the PS-CoAl LDHs. Moreover, the surface amorphization could increase the flexibility of the structure to provide abundant unsaturated sites. Thus, the PS-CoAl LDHs showed a lower overpotential of $329 \mathrm{mV}$ at the current density of $10 \mathrm{~mA} \mathrm{~cm}^{-2}$ and possessed faster reaction kinetics during the OER process compared to the CoAl LDHs. Qian et al. also reported S-doped Co-Ni LDHs on conductive substrates through a one-step electrodeposition method [97]. The S-doped Co-Ni LDHs with improved conductivity yielded higher electrocatalytic activities than the undoped one. Recently, $\mathrm{Lu}$ and co-workers [98] also reported the template-directed synthesis of the three-dimensional (3D) porous sulfur which incorporated the NiCoFe LDH nanosheets (S-NiCoFe LDH) in the carbon cloth. The 3D hierarchical porous nanosheets provided 
abundant active sites, and the doping with sulfur enhanced the electrical conductivity. Additionally, the as-prepared S-NiCoFe LDH showed excellent OER catalytic activity and increased stability.

\subsection{Nitrogen}

$\mathrm{N}$ doping is another effective way used to promote the electrochemical performance. Specifically, introducing $\mathrm{N}$ into the lattice could optimize the catalytic performance by overcoming the intrinsic activation barrier during the catalytic reaction [94]. Recently, Wang's group [99] reported exfoliated and edge-rich ultrathin CoFe LDHs nanosheets with nitrogen doping (denoted as $\mathrm{N}-\mathrm{CoFe} \mathrm{LDHs}$ ) as the OER electrocatalyst. The $\mathrm{N}$-CoFe LDHs were synthesized by treating the bulk CoFe LDHs with the $\mathrm{N}_{2}$ plasma. After the $\mathrm{N}_{2}$ plasma treatment, the morphology of the hexagonal nanosheet structure was maintained as shown in the SEM and TEM images (Fig. 4(A) and (B)). The atomic force microscopy (AFM) images (Fig. 4(C)) showed that the thicknesses of the $\mathrm{N}-\mathrm{CoFe} \mathrm{LDHs}$ nanosheets $(1.6 \mathrm{~nm})$ were much smaller than the bulk CoFe LDHs (20.01 nm), thus suggesting that the bulk CoFe LDHs was efficiently exfoliated. The EDX results indicated that the $\mathrm{N}$ element was successfully introduced to the ultrathin CoFe LDHs nanosheets (Fig. 4(D)). The XPS results confirmed the presence of $\mathrm{Co}^{3+}$, nitrogen, and the increased content of oxygen vacancies in ultrathin $\mathrm{N}-\mathrm{CoFe}$ LDHs nanosheets (Fig. 4(E)). The linear sweep voltammetry
(LSV) curves of bulk CoFe LDHs and ultrathin N-CoFe LDHs nanosheets in $1 \mathrm{~mol} / \mathrm{L} \mathrm{KOH}$ electrolyte are presented in Fig. 4(F). The ultrathin N-CoFe LDHs nanosheets exhibited an outstanding OER performance with a lower overpotential of 281 $\mathrm{mV}$ at $10 \mathrm{~mA} \mathrm{~cm}^{-2}$ and a smaller Tafel slope of $40.03 \mathrm{mV} \mathrm{\textrm {dec } ^ { - 1 }}$ compared to the bulk CoFe LDHs. The significantly increased electrocatalytic activity was attributed to the ultrathin nanosheet structure which had an increased number of reactive sites, an increased number of dangling bonds, and a lower number of coordination atoms caused by efficient plasma exfoliation. In addition, nitrogen doping could alter efficiently the electronic arrangement of the adjacent Co or Fe atoms to facilitate the adsorption of OER intermediates.

\section{Defect engineering}

Previous results confirmed that the surface defects may have a positive effect on the electrochemical reaction $[100,101]$. Defects in catalysts can tune the electronic structure and surface properties of nanomaterials by changing the distribution of electronic charge and by increasing the degree of disorder [102]. Additionally, the formation of the lower coordination number of metal atoms with high-energy hanging bonds through defect engineering is conducive in the increase of the catalytic performance of the reactive sites $[103,104]$. Anionic vacancies (such as oxygen vacancies) are the most common vacancies in transition metal compounds. The pres-
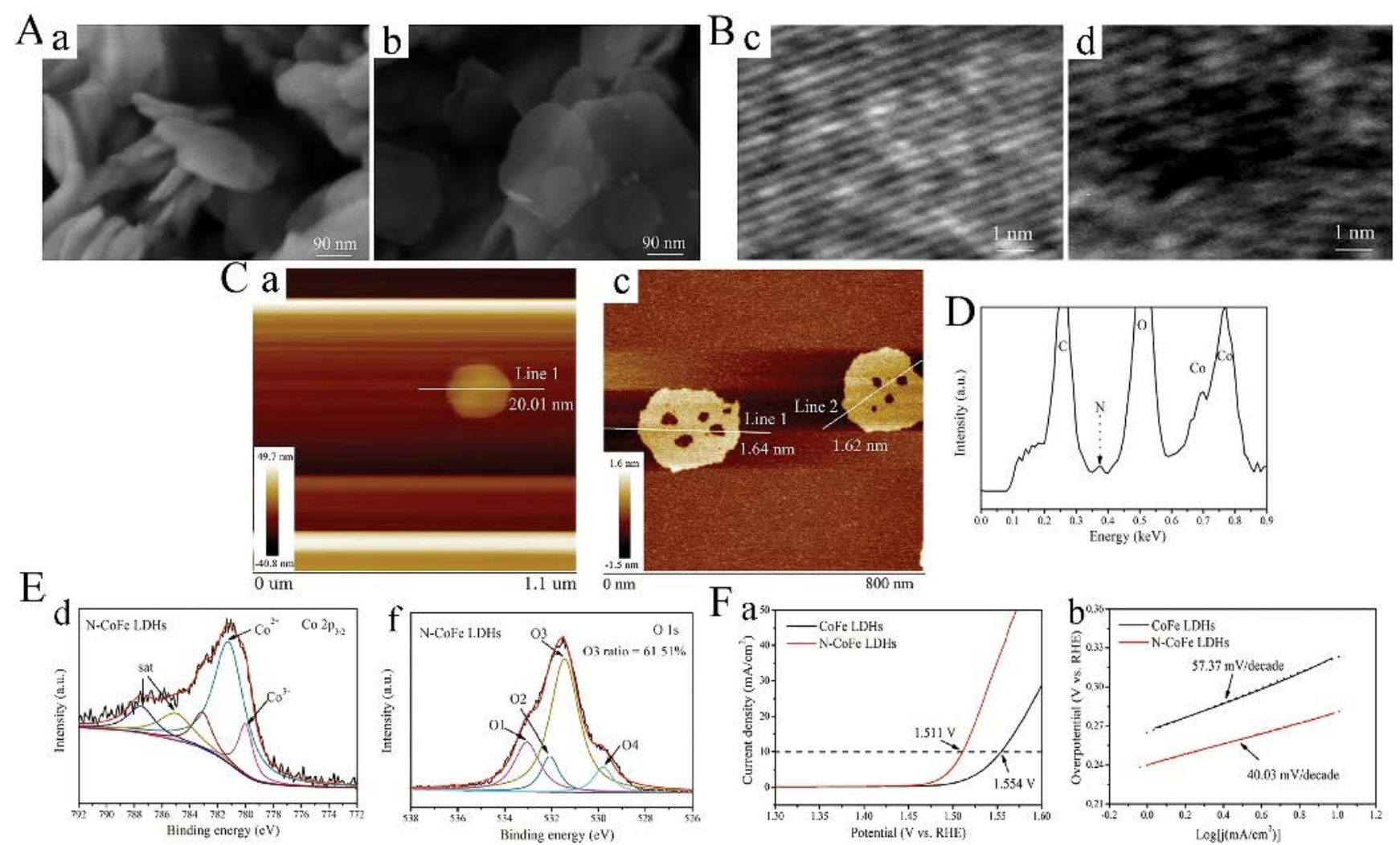

Fig. 4. (A) SEM images of the (A) CoFe LDHs and (B) ultrathin N-CoFe LDHs nanosheets. (B) HRTEM images of (C) CoFe LDHs and (D) the ultrathin $\mathrm{N}$-CoFe LDHs nanosheets. (C) AFM images of (A) the bulk CoFe LDHs and (C) the ultrathin N-CoFe LDHs nanosheets. (D) Corresponding EDX images for ultrathin N-CoFe LDHs nanosheets. (E) XPS spectra of (D) Co 2p3/2 and (F) $01 s$ of the ultrathin CoFe LDHs nanosheets. (F) (A) LSV polarization curves and (B) Tafel plots of bulk CoFe LDHs and ultrathin N-CoFe LDHs nanosheets at the scan of $5 \mathrm{mV} \mathrm{s}^{-1}$ [99]. Reprinted with permission from [99]. 
ence of anionic vacancies in a catalyst can adjust its surface electronic properties and bandgap to greatly change its physical and chemical properties [105,106]. For example, Wang's group [61] designed a $\mathrm{Co}_{3} \mathrm{O}_{4}$-based OER electrocatalyst with oxygen vacancies and high-surface area by an $\mathrm{Ar}$ plasma-engraving strategy. In this case, the plasma treatment could effectively engrave the $\mathrm{Co}_{3} \mathrm{O}_{4}$ nanosheet structure to increase the surface area. In addition, the plasma-engraved $\mathrm{Co}_{3} \mathrm{O}_{4}$ with oxygen vacancies on its surface could expose more surface sites to significantly enhance its electrocatalytic activity for OER. In addition to anionic vacancies, cationic vacancies also have considerable effects on the OER performance. The introduction of metal cationic vacancies in the catalyst can alter the valence state of the adjacent metal sites to enhance its electrochemical performance [107]. For instance, Wang's group [57] synthesized the SnCoFe perovskite hydroxide with abundant Sn vacancies by Ar plasma. In this study, it was preferred to produce Sn vacancies instead of Co or Fe vacancies owing to the relatively lower lattice energy and weaker chemical bonds of $\mathrm{Sn}(\mathrm{OH})_{4}$. The as-formed Sn vacancies could promote the exposure of additional CoFe sites, form an amorphous surface layer to effectively regulate the surface electronic structure and lead to a significant enhancement of the OER activity. Moreover, other types of defects (such as lattice dislocations, expansion, and distortion have also been extensively investigated. Therefore, the defect engineering of electrocatalysts is considered to be an effective method that is used to improve the catalytic activity.

\subsection{Anionic vacancies}

Oxygen vacancies are most common in anionic vacancies [108]. Suitable oxygen vacancies can tune the electronic structure of the catalyst, increase the active sites, improve its electrical conductivity, and optimize the adsorption energies of its OER intermediates $[109,110]$. Furthermore, oxygen vacancies can serve as the active sites of catalytic reactions [111]. There are several ways to generate vacancies. The reduction, thermal treatment, corrosion, and plasma technology are the most common strategies used to create vacancies [112]. Specifically, the use of different reducing agents can generate anionic vacancies [113]. In thermal treatments, reducing agents regulate the formation of vacancies mainly related to the carrier gas, annealing temperature, and heating ramp rates [114]. In addition, plasma technology is a quick and convenient approach used in vacancy engineering and has been extensively investigated [57]. For example, Yang's group [115] demonstrated that the exfoliated CoFe LDH nanosheets with rich oxygen vacancies could be used as bifunctional electrocatalysts. The CoFe LDHs-C $\left(\mathrm{CO}_{3}{ }^{2-}\right.$ as intercalated anions) was treated with $\mathrm{N}$, $\mathrm{N}$-dimethylformamide (DMF) and was mixed with ethanol as a solvent to obtain CoFe LDH-F ( $\mathrm{F}^{-}$as intercalated anions). Compared to CoFe LDH-C, the as-obtained CoFe LDH-F had thinner structures and more defect sites (oxygen vacancies), which could create more unsaturated metals as active sites and improve their intrinsic electronic conductivities. Therefore, the CoFe LDH-F exhibited a remarkable electrocatalytic perfor- mance. Besides, Xiong et al. [62] introduced oxygen vacancy defects on the surface of NiFe LDH by the treatment with $\mathrm{NaBH}_{4}$. Compared to pristine NiFe LDH, the as-designed defective $\mathrm{NiFe} \mathrm{LDH}$ electrocatalysts exhibited a significantly enhanced OER activity with a low-onset potential of $1.40 \mathrm{~V}$ and a small overpotential of $200 \mathrm{mV}$ to derive the current density of $10 \mathrm{~mA} \mathrm{~cm}-2$. The DFT+U calculations revealed that the introduction of oxygen vacancies tended to reduce the valence state of $\mathrm{Fe}$ and narrow the bandgap so that the electrons could be easily excited into the conduction band, thus leading to an enhanced conductivity and to an improved OER performance. It is concluded that the superior OER activity of defective NiFe LDH was owing to the tuned electronic structure, enhanced electrical conductivity, and improved exposed active sites.

\subsection{Cationic vacancies}

According to previous publications, the metal cationic vacancies usually have a positive effect on the electrochemical reactions for their various electron and orbit distributions [104]. The introduction of metal cationic vacancies can regulate the surface electronic structure around the reactive sites to facilitate the adsorption of OER intermediates, thus leading to a significantly improved electrocatalytic activity $[32,116]$. However, compared to anionic vacancies, the formation energy of cationic vacancies is large, which makes it more difficult to study its role [104]. Recently, Sun's group [117] prepared a NiFe LDH with atomic M(II)/M(III) defects as highly efficient OER catalysts. In this study, base-soluble $\mathrm{Zn}$ (II) or $\mathrm{Al}(\mathrm{III})$ atoms were introduced into the lattices of NiFe LDHs which were then selectively etched to create atomic M(II)/M(III) defects. Electrochemical results showed that M(II) defect-rich NiFe LDHs were superior to those of M(III) defect-rich NiFe LDHs. The DFT calculations revealed that the generation of many unsaturated $\mathrm{O}$-coordinations of the $\mathrm{Ni}(\mathrm{II})-\mathrm{O}-\mathrm{Fe}(\mathrm{III})$ coupling sites by selective defect engineering decreased the Gibbs free energy of the deprotonation step. Therefore, it can be concluded that the increased ECSA and changed electronic structures of the metal sites around the atomic defects could significantly enhance the OER activity.

Furthermore, Wang's group [63] designed two NiFe LDHs nanosheets with $\mathrm{Ni}^{2+}$ or $\mathrm{Fe}^{3+}$ vacancies as OER electrocatalysts, as shown in Fig. 5(A). In this study, NiFe LDHs nanosheets with $\mathrm{Ni}^{2+}$ vacancies (denoted as $\mathrm{NiFe}$ LDHs- $\mathrm{VNi}_{\mathrm{Ni}}$ ) or $\mathrm{Fe}^{3+}$ vacancies (denoted as $\mathrm{NiFe}$ LDHs- $\mathrm{V}_{\mathrm{Fe}}$ ) were obtained by etching the as-synthesized NiZnFe LDHs and NiFeAl LDHs nanosheets. According to the XRD patterns, the as-obtained NiFe LDHs- $\mathrm{V}_{\mathrm{Fe}}$ and NiFe LDHs- $\mathrm{V}_{\mathrm{Ni}}$ maintain the host crystal structure of $\mathrm{NiFe}$ LDHs (Fig. 5(B)). The NiFe LDHs- $\mathrm{V}_{\mathrm{Fe}}$ and NiFe LDHs- $\mathrm{V}_{\mathrm{Ni}}$ maintain their plate-like morphologies. The Ni $2 p_{3 / 2}$ XPS spectrum (Fig. 5(C)) of NiFe LDHs, NiFe LDHs- $\mathrm{V}_{\mathrm{Fe}}$, and NiFe LDHs- $\mathrm{V}_{\mathrm{Ni}}$, reveal that the introduction of iron or nickel vacancies caused the chemical valence state to increase from $\mathrm{Ni}^{2+}$ to $\mathrm{Ni}^{3+}$, which effectively regulates the surface electronic structure of the $\mathrm{NiFe}$ LDHs nanosheets. Thus, the NiFe LDHs- $\mathrm{V}_{\mathrm{Fe}}$ and NiFe LDHs- $\mathrm{V}_{\mathrm{Ni}}$ nanosheets yield better OER catalytic activities with lower overpotentials equal to 245 and $229 \mathrm{mV}$ at the current density 

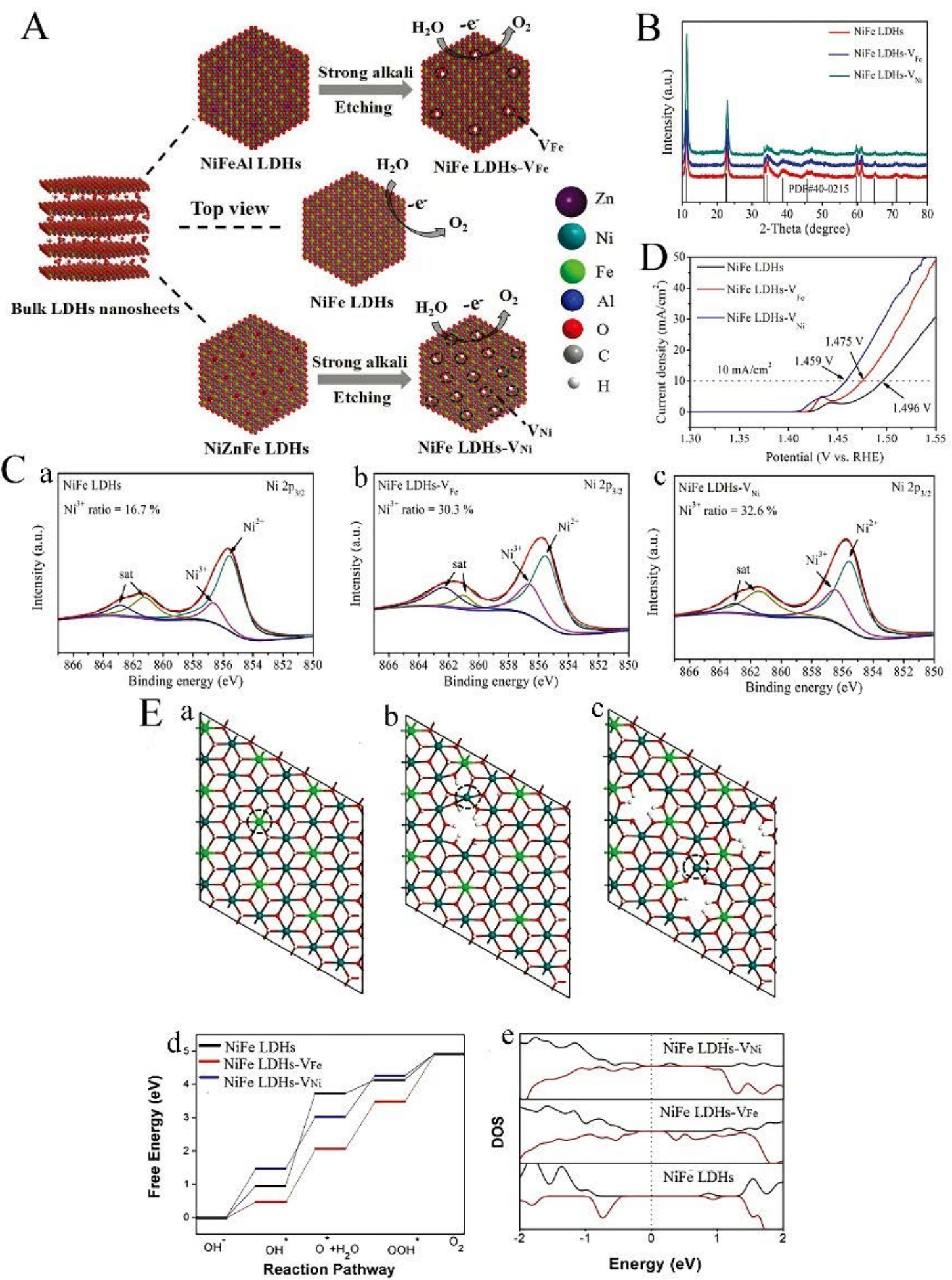

Fig. 5. (A) The synthesis of NiFe LDHs- $\mathrm{V}_{\mathrm{Fe}}$ and NiFe LDHs- $\mathrm{V}_{\mathrm{Ni}}$ by strong alkali etching LDHs. (B) XRD patterns of NiFe LDHs, NiFe LDHs-V $\mathrm{V}_{\mathrm{Fe}}$ and NiFe LDHs- $\mathrm{V}_{\mathrm{Ni}}$ nanosheets. (C) the Ni $2 p_{2 / 3}$ XPS spectra of the NiFe LDHs nanosheets (A), NiFe LDHs- $\mathrm{V}_{\mathrm{Fe}}$ nanosheets (B), and NiFe LDHs- $\mathrm{V}_{\mathrm{Ni}}$ nanosheets (C). (D) OER performance of NiFe LDHs, NiFe LDHs- $\mathrm{V}_{\mathrm{Fe}}$, and NiFe LDHs- $\mathrm{V}_{\mathrm{Ni}}$ nanosheets. (E) Top views of optimized geometries of pristine NiFe LDHs nanosheets (A), NiFe LDHs- $\mathrm{V}_{\mathrm{Fe}}(\mathrm{B})$, and $\mathrm{NiFe} \mathrm{LDH}-\mathrm{V}_{\mathrm{Ni}}(\mathrm{C})$, the blue, green, red, and white balls respectively represent the $\mathrm{Ni}, \mathrm{Fe}, \mathrm{O}$, and $\mathrm{H}$ atoms; (D) Free energy profile for the OER pathway; (E) density of states of three structures [63]. Reprinted with permission from [63].

of $10 \mathrm{~mA} \mathrm{~cm}-2$ compared to NiFe LDHs of $266 \mathrm{mV}$ (Fig. 5(D)). The improvement of the OER performance was attributed to the optimized surface electronic structure of the active sites around $\mathrm{Fe}$, or the Ni vacancies and the unsaturated coordinated sites generated by the introduction of the Fe or Ni vacancies. Spin-polarized density functional theory computations suggested that $\mathrm{Fe}^{3+}$ or $\mathrm{Ni}^{2+}$ vacancies facilitated the adsorption of O* intermediates (Fig. 5(E)). Furthermore, the electric density 
of state computations revealed that the presence of $\mathrm{Fe}$ or $\mathrm{Ni}$ vacancies lowered the bandgap and improved the electrical conductivity of NiFe LDHs.

\subsection{Multiple vacancies}

According to the discussion outlined above, it is deduced that the introduction of oxygen and metal vacancies into nanomaterials cannot only decrease the coordination number of catalytic sites but can also regulate the electronic structure of the electrocatalyst [107]. Recently, Wang's group [107] developed an Ar plasma technology to etch bulk CoFe LDHs to obtain ultrathin LDH nanosheets as an excellent electrocatalyst for the OER, as shown in Fig. 6(A). Ar plasma treatment could preserve the nanosheet structure during the exfoliation process. The AFM confirmed that the thickness of the ultrathin LDH nanosheet (denoted as CoFe LDHs-Ar) is equal to $0.6 \mathrm{~nm}$, and that it is smaller than that for pristine CoFe LDH, which is equal to $20.6 \mathrm{~nm}$ (Fig. 6(B)). The diffraction peaks corresponding to the disappearance of the 003 and 006 planes on the XRD pattern show that the LDHs nanosheets are successfully exfoliated into monolayer nanosheets (Fig. 6(C)). The XANES spectroscopy results indicate the presence of multiple vacancies $\left(\mathrm{V}_{\mathrm{o}}, \mathrm{V}_{\mathrm{Co}}\right.$, and $\mathrm{V}_{\mathrm{Fe}}$ ) in the ultrathin CoFe LDHs-Ar nanosheets (Fig. 6(D)). The electrochemical data show that the CoFe LDHs-Ar exhibit an enhanced OER activity compared to the bulk CoFe LDHs (Fig. 6(E)). The increased performance of the CoFe LDHs-Ar nanosheets could be attributed to the following factors: (1) the as-obtained ultrathin nanosheet structure with a larger surface area for the exposure of more active sites owing to Ar plasma etching, and (2) the formation of multiple vacancies for tuning the surface electronic structure, which leads to the decrease of the coordination numbers and the increase of the structural distortion.

Furthermore, ultrathin CoFe LDHs nanosheets with multivacancies which were obtained by a water plasma treatment were proved to be an efficient OER electrocatalyst according to Wang's group [118]. In this case, the water-plasma exfoliated CoFe LDHs nanosheets led to an enhanced electrocatalytic activity for OERs compared to pristine CoFe LDHs. This was ascribed to the structures of the ultrathin nanosheets increased surface areas that generated multivacancies ( $\mathrm{O}$, Co, and Fe vacancies) with lower coordination numbers, increased structure distortion, and dangling bands on the surface. Wang's group [119] also reported an excellent OER electrocatalyst of CoFe LDHs using an acid etching method. In this study, the acid

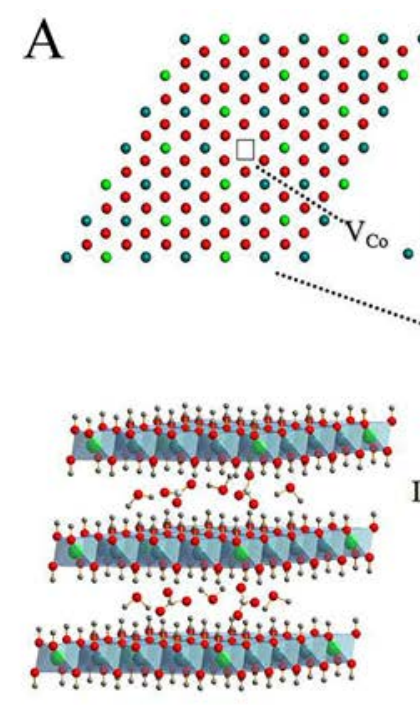

D

Bulk CoFe LDHs

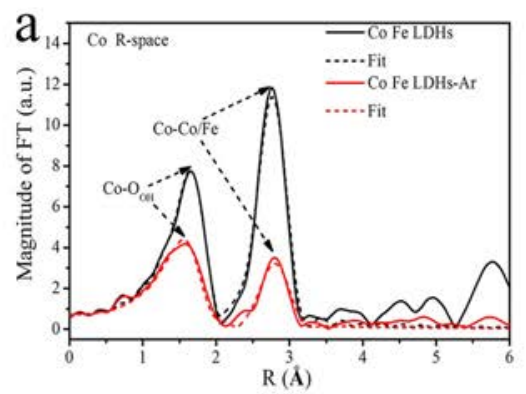

\section{Dry Exfoliation}
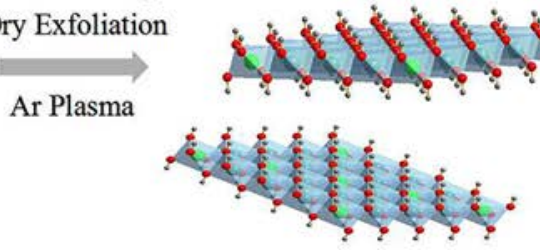

Ultrathin $\mathrm{CoFe}$ LDHs nanosheets

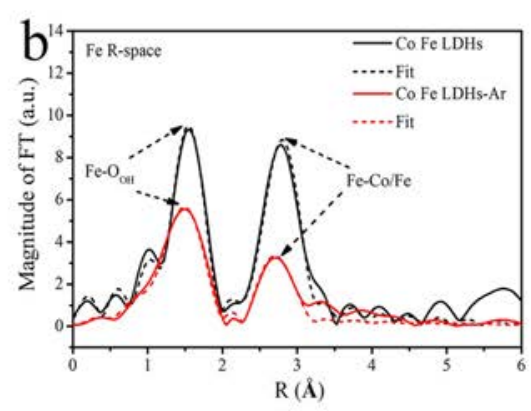

B
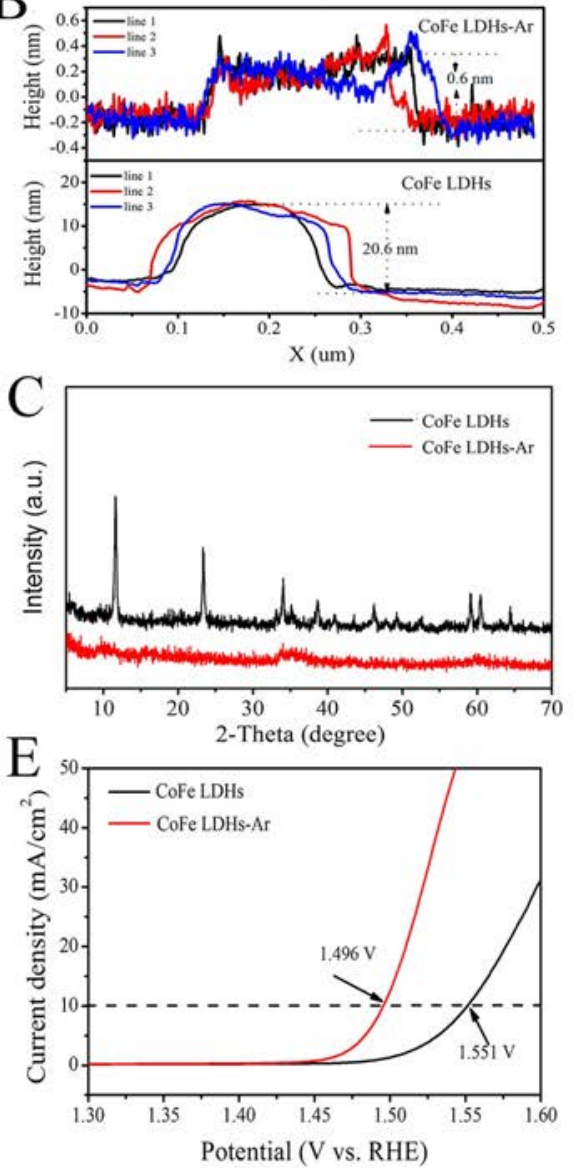

Fig. 6. (A) CoFe LDH nanosheets by Ar plasma exfoliation. (B) AFM images of corresponding height curves of bulk CoFe LDHs and ultrathin CoFe LDHs-Ar nanosheets. (C) XRD patterns of the bulk CoFe LDHs and ultrathin CoFe LDHs-Ar nanosheets. (D) magnitude of $\mathrm{k}^{3}$-weighted Fourier transforms of the Co edge (a) and Fe edge XANES spectra (b) for bulk CoFe LDHs and ultrathin CoFe LDHs-Ar; (E) LSV curves of bulk CoFe LDHs and ultrathin CoFe LDHs-Ar nanosheets for the OER at a scan rate of $5 \mathrm{mV} \mathrm{s}^{-1}$ [107]. Reprinted with permission from [107]. 
etched CoFe LDHs (denoted as E-CoFe LDHs) were prepared by immersing pristine CoFe LDHs into $1 \mathrm{M} \mathrm{HNO}_{3}$. After their treatment with $\mathrm{HNO}_{3}$, the regular and smooth nanosheets became smaller and contained multiple holes, while $\mathrm{CO}_{3}{ }^{2-}$ was partially replaced by $\mathrm{NO}_{3}{ }^{-}$in the acid etching process. The XANES analysis indicated the appearance of multiple defects $(\mathrm{O}, \mathrm{Co}$, and Fe vacancies) in the exfoliation process. The E-CoFe LDHs yielded a superior OER activity with the lower potential of $1.576 \mathrm{~V}$ to generate the current density of $10 \mathrm{~mA} \mathrm{~cm}^{-2}$, and a lower Tafel slope of $41 \mathrm{mV} \mathrm{dec}^{-1}$ compared to the pristine CoFe LDHs of $1.532 \mathrm{~V}$ and $78 \mathrm{mV} \mathrm{dec}^{-1}$. This was owing to the larger interlayer space caused by the intercalation of some $\mathrm{NO}_{3}{ }^{-}$, tuning of the electronic properties, increased degree of disorder, and the exposure of more active sites by the multiple vacancies. At the same time, a two-dimensional (2D) single-unit-cell-thick LDH nanosheets $(\sim 1.3 \mathrm{~nm})$ catalyst for OER was prepared by reducing the reaction time to $5 \mathrm{~min}$ [120]. Owing to the ultrathin structure which had more surface defects, increased active site density, and an enhanced electrical conductivity, an improved electrocatalytic activity on the OER results compared to that of the bulk LDHs.

\section{4. $\quad$ Other defect engineering}

In addition to the aforementioned defect types, many types of lattice defects (such as lattice dislocations, expansion, and distortion) also have positive effects on the promotion of electrocatalysis [121-122]. These defects can effectively regulate the electronic structure and optimize the electrocatalytic performance [104]. They can be generated by doping, substitution, etching, and amorphization [104]. For example, Tang and co-workers [123] introduced the NiFe LDH nanosheet array catalyst with partially amorphous characteristics. The results revealed that partially amorphous NiFe LDH possessed native $\mathrm{Ni}^{3+}$ ions compared to the highly crystalline catalysts. Furthermore, partially amorphous NiFe LDH could not only provide abundant high-valence active sites for electrochemical reaction, but also generated abundant crystalline-amorphous interface to improve the electrical conductivity. Therefore, this compound exhibited enhanced OER activity than fully amorphous and highly crystalline catalysts. Correspondingly, Ni-Co amorphous double hydroxides (ADHs) nanocages were synthesized by Guo and co-workers [124]. The EXAFS results demonstrated that amorphous Ni-Co ADHs had a more pronounced structural disorder as compared to crystalline materials. Accordingly, it had a higher surface reactivity and structural stability in promoting its OER activity. Yang and co-workers [125] synthesized ultrathin NiAl-LDH nanosheets using the one-step liquid-phase exfoliation method. The exfoliation process of LDHs resulted in the formation of Ni (III) active sites. Yan et al. [126] presented ultrathin NiFe LDH nanosheets as efficient OER catalysts. The enhanced OER activity was ascribed to a better conductivity and to the large specific surface area owing to exfoliation. Tang and co-workers reported a facile in situ self-assembly strategy that was used to synthesize Ce-doped NiFe-LDH on CNT [71]. Compared to the pristine NiFe-LDH, the Ce-doped NiFe-LDH exhibited better OER performance. The enhanced OER activity was derived from the doping of $\mathrm{Ce}^{3+}$ in NiFe-LDH which led to lattice defects and induced imperfections in the layers. The lattice defects could induce the formation of thin nanosheet structures to expose more active sites.

\section{Intercalated anion regulation}

The intercalated anion regulation of LDHs electrocatalysts is another effective way to improve the OER performance, which can in turn improve the ion exchange capacity, enlarge the interlayer distance, facilitate diffusion of the reactants and products, and enhance its intrinsic catalytic activity [54,127,128]. Initially, most studies focused on the introduction of different inorganic nonmetal anions in LDHs. Sun and co-workers synthesized NiFe LDHs with different anion intercalations at room temperature as an excellent oxygen evolution catalyst [129]. In this study, different interlayer ions could be achieved by changing the ratio of $\mathrm{NO}_{3}{ }^{-}$and $\mathrm{CO}_{3}{ }^{2-}$ in the synthesis process. Increased $\mathrm{NO}_{3}{ }^{-}$intercalation of NiFe-LDH led to superior OER activities with a low-onset overpotential equal to $240 \mathrm{mV}$, and a

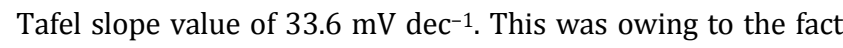
that the wider interlayer space could expose more active sites, promote the anion-exchange ability, and decrease the charger transfer resistance. Additionally, Chen and co-workers [130] reported the NiCo-LDH hollow nanoprism (HNP) intercalated with multiple anions (including $\mathrm{CH}_{3} \mathrm{COO}^{-}, \mathrm{NO}_{3}{ }^{-}, \mathrm{OH}^{-}$, and $\mathrm{CO}_{3}{ }^{2-}$ ) through a facile sacrificial template route. The NiCo-LDH HNP yielded an enlarged interlayer spacing and an increased specific surface area achieved by the intercalation of multiple anions, which was favorable for accelerating the insertion of electrolyte ions and transport. In addition, the hollow architecture facilitated the exposure of electroactive sites, and the transfer of mass and charge. Thus, NiCo-LDH HNP demonstrated an excellent electrocatalytic activity toward OER with a low overpotential of $0.35 \mathrm{~V}$ at $10 \mathrm{~mA} \mathrm{~cm}^{-2}$ and good stability.

Subsequently, Duan and co-workers [131] reported phosphorus-based (including phosphate, phosphite, and hypophosphite anions) NiFe-LDHs intercalated with oxoanions by a co-precipitation method that were used as oxygen evolution electrocatalysts. After the intercalation of the phosphorus oxoanion, NiFe-LDH had an enlarged interlamellar space compared to that of the carbonate counterpart. The XPS results revealed that the NiFe-LDHs intercalated with hypophosphite had a lower valence state than phosphate, or NiFe-LDHs intercalated with phosphite, thus suggesting that the intercalation of phosphorus oxoanion could alter the electronic structure of the $\mathrm{Ni}$ sites in the LDHs. The as-prepared NiFe-LDH intercalated with hypophosphite yielded an excellent OER performance with the smallest onset potential of $1.45 \mathrm{~V}$ and a smaller Tafel slope of $37.7 \mathrm{mV} \mathrm{dec}^{-1}$, which was superior to that of the phosphite, phosphate, and NiFe-LDH catalysts intercalated with carbonate. The enhanced OER activity was attributed to the tuned electronic structure of the surface $\mathrm{Ni}$ sites by the intercalated hypophosphite anions. Meanwhile, $\mathrm{Li}$ and co-workers synthesized borate, ion-intercalated, Ni-Fe LDH nanosheets as an efficient electrocatalyst for OERs [132]. The Ni-Fe LDH with borate ion intercalation yielded an expanded interlayer dis- 
tance and an increased pore size compared to the bulk Ni-Fe LDH. In addition, the increased specific surface area achieved by the intercalation of the borate ion could facilitate mass transport and charge transfer. Thus, after borate ion intercalation, the Ni-Fe LDH exhibited the optimal OER electrocatalytic activity with a low-onset overpotential of $270 \mathrm{mV}$ and a Tafel slope of $42 \mathrm{mV} \mathrm{dec}-1$.

In addition to inorganic nonmetal anions, inorganic metal anions have been extensively studied. Ultrathin NiFe-LDH nanosheets intercalated with molybdate anions were prepared by Li's group [133]. After the intercalation of molybdate ions, the thickness of NiFe-LDH nanosheets was $0.5 \mathrm{~nm}$ and the interlayer distance was $0.7 \mathrm{~nm}$, thus confirming the intercalation of molybdate ions and the formation of the ultrathin structure with an enlarged interlayer distance. Thus, the ultrathin $\mathrm{NiFe}-\mathrm{LDH}$ nanosheets possessed a better OER activity with a low overpotential of $280 \mathrm{mV}$ to drive the current density to 10 $\mathrm{mA} \mathrm{cm}-2$, and good electrochemical stability compared to the regular NiFe-LDH. Moreover, Zn-Fe LDHs intercalated with vanadate and molybdate anions were also fabricated by Rezvani and co-workers using a co-precipitation method [134]. During the intercalation of the vanadate and molybdate anions, the interlayer spacing of LDHs had not changed. The Zn-Fe LDHs with the vanadate anion intercalation yielded an increased OER activity with a smaller overpotential in $0.1 \mathrm{~mol} / \mathrm{L} \mathrm{KOH}$. It also yielded a stronger durability with the intercalation of vanadate anion compared to Zn-Fe LDHs and Zn-Fe LDHs with the intercalation of molybdate anion. This was owing to the increased catalytic active sites that facilitated electrode charge transfer.

To understand the effect of interlayer spacing and interlayer ions on OER activity, many studies have been conducted. Guan and co-workers [128] investigated the correlation between the interlayer distance and the OER catalytic performance of the electrodeposited NiFe LDH with formamide as the intercalated anion using the in situ intercalation method. In this study, the interlayer distance of NiFe LDH was increased from 7.8 to $9.5 \AA$ by the immersion of the electrode in formamide. After the immersion of the NiFe LDH electrode in formamide with ultrasound, the intercalated electrodes yielded lower overpotentials and higher current densities at a specific potential, and larger TOFs than the original NiFe LDH electrode. The reason for the enhancement was attributed to the fact that the extension of the interlayer distance could expose more catalytic sites and facilitate the diffusion of the reactants and products. Müller and co-workers [135] prepared a series of NiFe-LDH nanosheets with different interlayer anions to study the role of intercalated anions on the OER activity. The incorporation of different interlayer anions in the NiFe-LDH nanosheets was achieved by pulsed laser ablation in liquids (PLAL) or anion exchange. It was found that the measured basal spacings of LDH nanosheets were linearly related to the interlayer anion radius. Surprisingly, the overpotentials did not depend on the basal spacings. The OER activity was correlated to the $\mathrm{pKa}$ of the conjugate acid of the interlayer anions. Specifically, the $\mathrm{pKa}$ of the anion could bind to the active iron sites in the catalyst to influence their OER activities. Thus, the higher $\mathrm{pKa}$ value of the conjugate acid of the interlayer anion is the result of its higher OER activity.
Recently, Yang and co-workers [136] synthesized a series of NiFe LDH materials with different interlayer anions, including carbonate $\left(\mathrm{CO}_{3}{ }^{2-}\left(\mathrm{H}_{2} \mathrm{O}\right)\right.$ and $\left.\mathrm{CO}_{3}{ }^{2-}(\mathrm{EtOH})\right)$, chloride $\left(\mathrm{Cl}^{-}(\mathrm{EtOH})\right)$ and sulfate $\left(\mathrm{SO}_{4}{ }^{2-}(\mathrm{EG})\right)$, with one-step hydrothermal synthesis, as shown in Fig. 7(A). The powder X-ray diffraction (PXRD) pattern (Fig. 7(B)) suggests that the crystalline domain size of the $\mathrm{CO}_{3}{ }^{2-}(\mathrm{EtOH})$ sample is smaller than that of the $\mathrm{CO}_{3}{ }^{2-}\left(\mathrm{H}_{2} \mathrm{O}\right)$ sample. Additionally, the $\mathrm{Cl}^{-}(\mathrm{EtOH})$ sample has a larger interlayer spacing compared to that of the $\mathrm{CO}_{3}{ }^{2-}\left(\mathrm{H}_{2} \mathrm{O}\right)$ sample, while the $\mathrm{SO}_{4}{ }^{2-}(\mathrm{EG})$ sample has a different crystal structure compared to other samples. The attenuated total reflectance infrared spectroscopy (ATR-IR) and the PXRD patterns confirmed that the $\mathrm{Cl}^{-}(\mathrm{EtOH})$ and $\mathrm{SO}_{4}{ }^{2-}(\mathrm{EG}) \mathrm{NiFe} \mathrm{LDH}$ samples contained a small amount of carbonate anions in the interlayer (Figure 7B). The OER electrocatalytic activity was evaluated in $1 \mathrm{~mol} / \mathrm{L}$ $\mathrm{KOH}$ (Fig. $7(\mathrm{C})$ ). Both the $\mathrm{CO}_{3}{ }^{2-}\left(\mathrm{H}_{2} \mathrm{O}\right)$ and $\mathrm{Cl}^{-}(\mathrm{EtOH})$ electrodes have a similar electrocatalytic performance with overpotentials of 341 and $343 \mathrm{mV}$ at a respective geometric current density of $10 \mathrm{~mA} \mathrm{~cm}-2$. These were better than those of the $\mathrm{CO}_{3}{ }^{2-}(\mathrm{EtOH})$ and $\mathrm{SO}_{4}{ }^{2-}(\mathrm{EG})$ electrodes which respectively equaled 486 and $375 \mathrm{mV}$. The respective normalized CV curves for $\mathrm{Cdl}_{\mathrm{dl}}$ and the $\mathrm{J}-\mathrm{V}$ curves are shown by the dashed traces in Fig. 7(C). There were no significant differences with the values normalized by the geometric area, thus indicating that these NiFe LDH catalysts with different interlayer anions $\left(\mathrm{CO}_{3}{ }^{2-}, \mathrm{Cl}^{-}, \mathrm{SO}_{4}{ }^{2-}\right)$ had the same intrinsic activities. Moreover, these interlayer anions were easily exchanged with carbonates in the OER electrolyte in ambient conditions. Furthermore, through anion exchange, the $\mathrm{Cl}^{-}(\mathrm{EtOH})$ powder was transformed into NiFe LDH intercalated with dodecyl sulfate anions (DS ${ }^{-}$) to study the impact of a large redox-inactive anion. The $\mathrm{DS}^{-}$intercalated NiFe LDH with larger interlayer spacings exhibit enhanced OER performance than the $\mathrm{LDH}$ with other intercalated anions $\left(\mathrm{CO}_{3}{ }^{2-}, \mathrm{Cl}^{-}, \mathrm{SO}_{4}{ }^{2-}\right)$, as shown in Fig. 7(C). Moreover, it could resist the anion exchange to form the carbonate LDH. This result showed that the DS- intercalated NiFe LDH possessed higher intrinsic catalytic activity than other samples.

In summary, the intercalation anion regulation of LDHs with a unique 2D layered structure can effectively improve the OER activity. Compared to the cationic/anionic regulation, the intercalated anion regulation can also promote the OER activity. However, it has a lesser effect on the crystal structure. The improved OER performance mainly included the (1) expansion of the interlayer spacing of the LDHs that increase electrochemically the active specific surface area and facilitate the diffusion of the reactants and products, and (2) increased the catalytic active sites by enhancing the intrinsic catalytic activities of the active sites.

\section{Surface modifications}

The surface modifications of LDHs with electronegative noble metals can effectively enhance their electrocatalytic activities $[110,137]$. The noble metals were combined with LDHs to form heterojunctions to facilitate the electron transfer and increase the interfacial interaction between the metal nanoparticles and LDHs layers [138,139]. Recently, Kundu and 

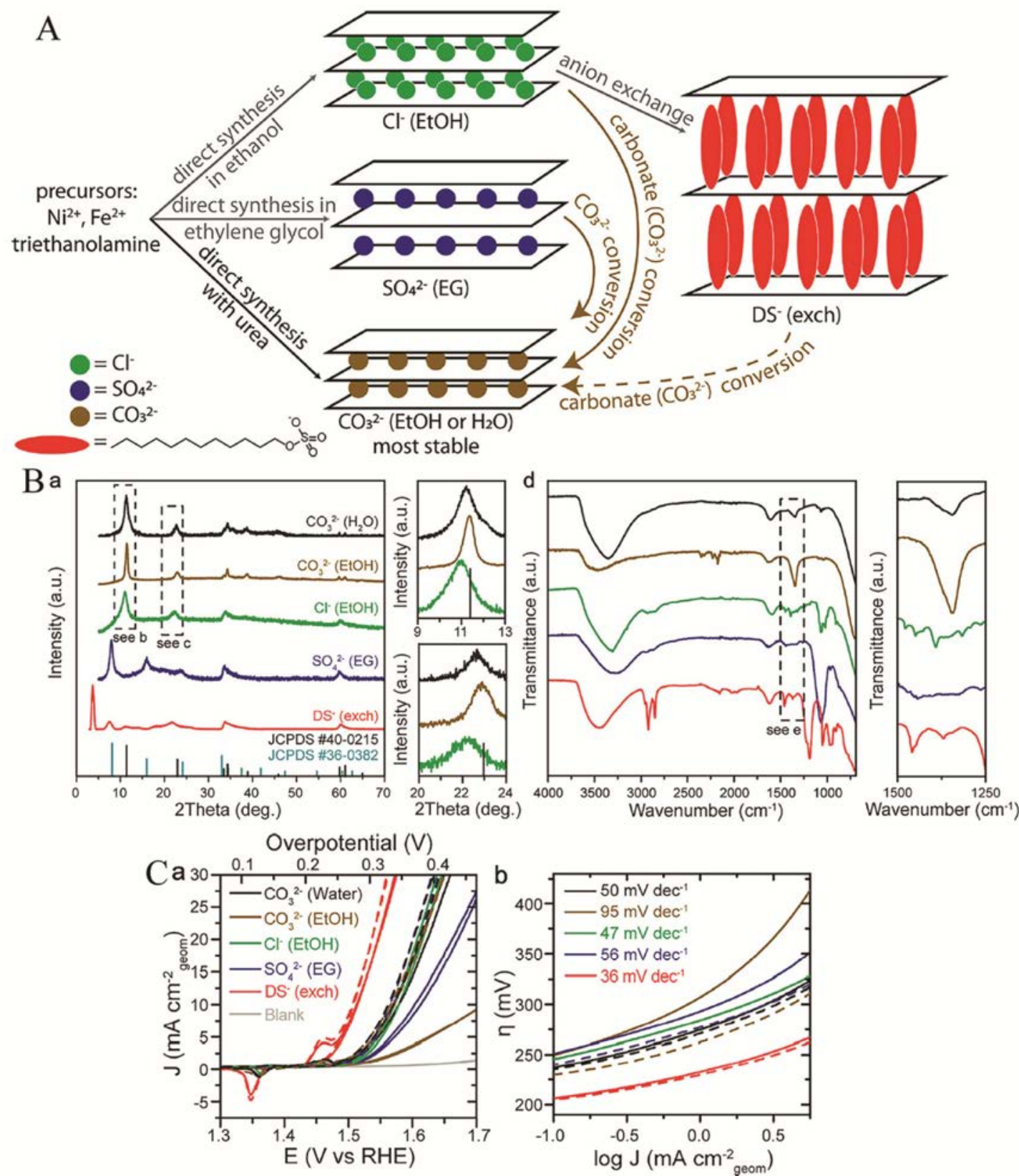

Fig. 7. (A) Schematic description of the synthetic procedures and anion exchange route showing the structural illustrations of NiFe LDH products containing carbonate, chloride, sulfate, and dodecyl sulfate anions in the interlayer gallery. (B) PXRD patterns (a) and ATR-IR spectra (d) of various NiFe LDH samples from different synthesizes. (C) The second CVs of each electrode before (solid) and after ECSA normalization (dashed) (a), and corresponding Tafel plots (b) [136]. Reprinted with permission from [136].

co-workers [140] reported an electrocatalyst with increased efficiency toward OER and HER of the NiFe LDH decorated with Pt nanoparticles (NPs) based on a two-step reaction. In this study, Pt-tethered, NiFe LDH crystalline sheets, showed that Pt NPs tethered uniformly on the surface of NiFe LDH crystalline sheets and their mean diameter was $4 \pm 1 \mathrm{~nm}$. Pt-NP tethered, $\mathrm{NiFe}$ LDH crystalline sheets, yielded a significantly enhanced OER activity with a lower overpotential of $280 \mathrm{mV}$ at $50 \mathrm{~mA}$ $\mathrm{cm}^{-2}$, a lower Tafel slope, and better stability than the co-precipitated NiFe LDH. Similarly, Pt-NP tethered, NiFe LDH crystalline sheets, showed a better activity toward HER. The enhanced OER performance of the Pt-NP tethered coprecipitated NiFe LDH was attributed to the large ECSA and the increased degree of crystallinity.

Hasheminasab and co-workers reported gold nanodendrite-CuMgFe LDH composites as a bifunctional electrocatalyst for OER and HER [141]. The Au nanodendrite-CuMgFe-LDH electrodes exhibited a lower onset potential in OERs compared 
to the $\mathrm{Au}$ CuMgFe-LDH and CuMgFe-LDH NPs. Moreover, Au CuMgFe-LDH nanodendrites also exhibited a much lower HER onset potential and a higher current density than other samples. This enhancement in catalytic activity could be related to the improved electrical conductivity, the increased active surface area, and the synergistic effect between the Au nanodendrites and the CuFeMg-LDH. Furthermore, Wang and coworkers constructed NiFe LDH nanoarrays with electronegative noble metals of $\mathrm{Au}$ on $\mathrm{Ni}$ foam (NiFe LDH@Au/Ni foam) for OER [142]. The highly electronegative Au could tune the electronic structure and the electron adsorption to generate and stabilize Ni cations to achieve the high oxidation state $\left(\mathrm{Ni}^{3+}\right)$, which facilitated the formation of the intermediate hydroperoxy species $(\mathrm{OOH})$. In addition, the unique 3D structure was beneficial in improving material conductivity and in increasing the number of active sites. Thus, the NiFe LDH@Au/Ni foam exhibited a superior OER catalytic performance with the lower overpotential of $243 \mathrm{mV}$ to achieve a current density of $100 \mathrm{~mA}$ $\mathrm{cm}^{-2}$ compared to the NiFe LDH/Ni foam.

Zhang and coworkers [143] synthesized SAu supported on $\mathrm{NiFe}$ LDH to predict and investigate the origin of OER activity. The DFT calculations plus the Hubbard-U approach results revealed that the $\mathrm{LDH}$ substrate and interlayer $\mathrm{CO}_{3}{ }^{2-}$ anions in ${ }^{\mathrm{s}} \mathrm{Au} / \mathrm{NiFe} \mathrm{LDH}$ maintained the charge balance of oxyhydroxide, and thus stabilized the surface $\mathrm{NiFeOOH}$ layer. This resulted in optimal adsorption energies for the OER intermediates on Fe active sites (Fig. 8(A)) [143]. The SEM and TEM images revealed that $\mathrm{S} \mathrm{Au} / \mathrm{NiFe} \mathrm{LDH}$ still maintain the nanosheet morphology of NiFe LDH without the nanoparticles (Fig. 8(B)). The XANES spectrum of $\mathrm{Au}$ indicates that ${ }^{\mathrm{S}} \mathrm{Au} / \mathrm{NiFe} \mathrm{LDH}$ has single-atom $\mathrm{Au}$ and an $\mathrm{Au}-\mathrm{O}$ bond distance, which is different from the metallic Au (Fig. 8(C)). The OER activity is examined in $1 \mathrm{~mol} / \mathrm{L} \mathrm{KOH} \mathrm{(Fig.} \mathrm{8(D)).} \mathrm{The}{ }^{\mathrm{S} A u} / \mathrm{NiFe} \mathrm{LDH}$ yielded a higher OER activity with a lower overpotential, a smaller Tafel slope, and a larger turnover frequency compared to the NiFe LDH. In situ Raman technology of $\mathrm{SAu} / \mathrm{NiFe} \mathrm{LDH}$ confirm that LDHs have been transformed into oxyhydroxides using the oxygen evolution potential, and act as the catalytic species for OER (Fig. 8(E)). In situ synthesized oxyhydroxide also formed the local $\mathrm{Au}$ catalyst interface sites to enhance the electrocatalytic performance.

\section{Conclusions and outlook}

In summary, LDH materials have been extensively studied in recent years as the most promising electrocatalysts for OER owing to their unique 2D layered structures, easily tailored properties, and chemical composition versatility. This review highlighted the progress of $\mathrm{LDH}$ materials in promoting the OER performances based on the regulation of their electronic structures. The electronic structure regulation of LDHs effectively enhanced the intrinsic activity of the active sites, which is an adopted strategy for designing highly efficient electrocatalysts for OER. Specifically, it promoted the OER activity by optimizing the composition, tuning defect/phase/interface, and regulated the interactions between active sites and reactants, intermediates, and products. We consider that the regulation of the electronic structure can be achieved through the following strategies:

(1) Cationic/Anionic regulation: The cationic/anionic regulation was demonstrated as an effective approach used to regulate the OER activity. This process involved the replacement of

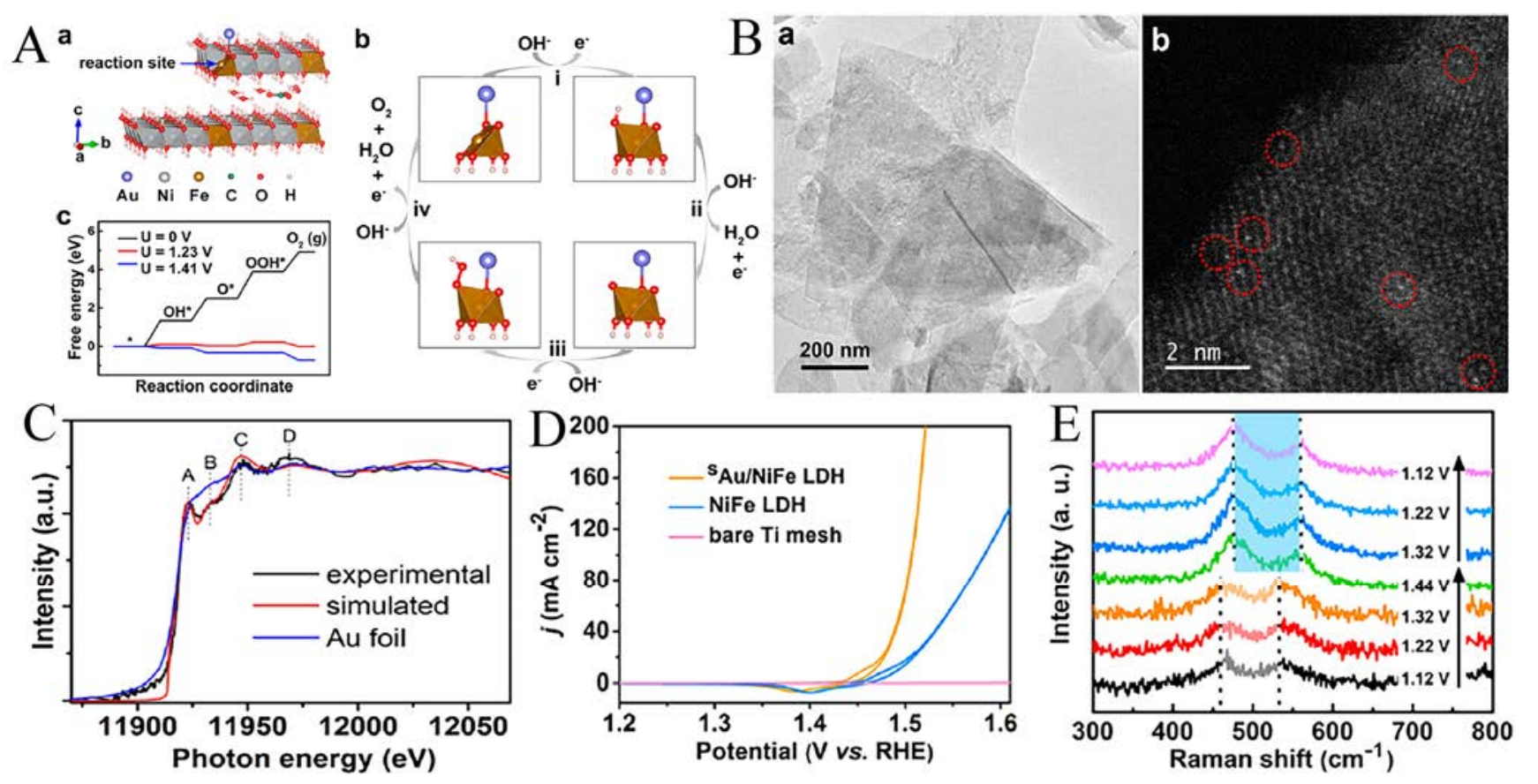

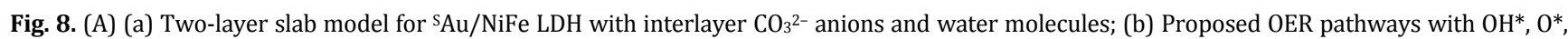
and $\mathrm{OOH}^{*}$ intermediates for ${ }^{\mathrm{S}} \mathrm{Au} / \mathrm{NiFe} \mathrm{LDH}$; (c) Free energy diagram for the OER at different potentials on the surface of the ${ }^{\mathrm{S}} \mathrm{Au} / \mathrm{NiFe} \mathrm{LDH}$ model. (B) TEM (a) and HAADF-STEM (b) images of ${ }^{\mathrm{S}} \mathrm{Au} / \mathrm{NiFe}$ LDH. (C) Au L $\mathrm{L}_{3}$-edge XANES spectra of the experimental and simulated results for ${ }^{\mathrm{S}} \mathrm{Au} / \mathrm{NiFe} \mathrm{LDH}$ as well as Au foil. (D) Cyclic voltammetry curves of ${ }^{\mathrm{S}} \mathrm{Au} / \mathrm{NiFe} \mathrm{LDH}$, pure NiFe LDH, and bare Ti mesh in $1 \mathrm{~mol} / \mathrm{L} \mathrm{KOH}$. (E) Raman spectra of ${ }^{\mathrm{s}} \mathrm{Au} / \mathrm{NiFe} \mathrm{LDH}$ at different potentials during anodic and cathodic sweeps in a CV cycle [143]. Reprinted with permission from [143]. 
cations/anions or the use of etching to form vacancies. Cationic/anionic regulation may tune the local coordination environment and fabricate the defect of catalysts to expose more active sites and enhance the electrical conductivity. Furthermore, doping atoms can serve as active sites to improve the intrinsic activity of LDHs catalysts

(2) Defect engineering: Introducing defects in the structure can regulate the electronic structure surrounding the active site near the defect site. Specifically, it changed the distribution of electronic charge and increased the degree of disorder and exposed more active sites. In addition, the presence of defects in the catalyst could create more surface metal atoms with a low-coordination number and more dangling bonds, thus leading to increased surface energy and to an improved number of electrocatalytic sites. When oxygen vacancies are introduced into the catalyst, the electronic structure of the catalyst, catalytically active sites, electrical conductivity, as well as adsorption energies of OER intermediates will be regulated. The introduction of metal cationic vacancies in the catalyst can adjust the valence state of nearby metal centers, and thus leads to an excellent OER activity

(3) Intercalated anion regulation: Intercalation of different anions was favorable for enlarging the interlayer distance to facilitate ion diffusion and increase the activity of the specific surface area. Moreover, the intercalated anions were able to regulate the electronic structure around the active site to effectively promote the intrinsic activity of the catalyst

(4) Surface modifications: Combined with the electronegative noble metals, they facilitated the electron transfer to effectively tune the electronic structure and form noble metal-catalyst interface sites. It was also beneficial to increase the electrical conductivity. Thus, the modified LDH catalysts by the noble metals showed enhanced electrocatalytic performances

However, the understanding of the catalytic mechanism of OER and the identification of catalytically active sites of LDHs is not enough. The understanding of the catalytic mechanism is beneficial for the rational design of catalysts. Moreover, determining the catalytically active sites of LDHs contributed to the understanding of how the interactions between metals improved the properties of the catalyst. Nevertheless, the definite roles of different metal ions in LDHs have not been determined yet. Although the electronic structure regulation is extensively used, it is not sufficient for the study of the effects of the interactions between electronic structure regulation and LDHs on the performance of electrocatalysts. For example, the understanding of the relationship between the catalytic activity and electronic structure needs to be enhanced. To accurately determine the regulation process and mechanism of catalysis, in situ or in operando techniques, and theoretical analyses, will be applied for future development. Additional research of the regulation of the electronic structure and highly active advanced energy materials are expected to be developed that will be suitable for water splitting or for use in other fields.

\section{References}

[1] M. Gong, H. Dai, Nano Res., 2015, 8, 23-29.
[2] X. Ren, R. Ge, Y. Zhang, D. Liu, D. Wu, X. Sun, B. Du, Q. Wei, J. Mater. Chem. A, 2017, 5, 7291-7294.

[3] J. Li, G. Du, X. Cheng, P. Feng, X. Luo, Chin. J Catal,, 2018, 39, 982-987.

[4] A. C. Thenuwara, S. L. Shumlas, N. H. Attanayake, Y. V. Aulin, I. G. Mckendry, Q. Qiao, Y. Zhu, E. Borguet, M. J. Zdilla, D. R. Strongin, ACS Catal., 2016, 6, 7739-7743.

[5] H. Lin, N. Liu, Z. Shi, Y. Guo, Y. Tang, Q. Gao, Adv. Funct. Mater., 2016, 26, 5590-5598.

[6] W. Xu, H. Wang, Chin.J Catal., 2017, 38, 991-1005.

[7] H. Li, Y. Tan, P. Liu, C. Guo, M. Luo, J. Han, T. Lin, F. Huang, M. Chen, Adv. Mater., 2016, 28, 8945-8949.

[8] R. Xiang, C. Tong, Y. Wang, L. Peng, Y. Nie, L. Li, X. Huang, Z. Wei, Chin. J Catal., 2018, 39, 1736-1745.

[9] C. G. Morales-Guio, L. Liardet, X. Hu, J. Am. Chem. Soc., 2016, 138, 8946-8957.

[10] L. Peng, S. S. A. Shah, Z. Wei, Chin. J Catal., 2018, 39, 1575-1593.

[11] H. Qian, J. Tang, Z. Wang, J. Kim, J. H. Kim, S. M. Alshehri, E. Yanmaz, X. Wang, Y. Yamauchi, Chem. Eur. J., 2016, 22, 18259-18264.

[12] F. Song, L. Bai, A. Moysiadou, S. Lee, C. Hu, L. Liardet, X. Hu, J. Am. Chem. Soc., 2018, 140, 7748-7759.

[13] N. T. Suen, S. F. Hung, Q. Quan, N. Zhang, Y. J. Xu, H. M. Chen, Chem. Soc. Rev., 2017, 46, 337-365.

[14] S. Sulay, K. Koshal, S. Sri, P. S. R. Ganesh, J. Indian Inst. Sci., 2016, 96, 325-350.

[15] A. Irshad, N. Munichandraiah, RSC Adv., 2016, 6, 30552-30563.

[16] X. Han, C. Yu, S. Zhou, C. Zhao, H. Huang, J. Yang, Z. Liu, J. Zhao, J. Qiu, Adv. Energy Mater., 2017, 7, 1602148.

[17] D. Zhou, L. He, R. Zhang, S. Hao, X. Hou, Z. Liu, G. Du, A. M. Asiri, C. Zheng, X. Sun, Chem. Eur. J., 2017, 23, 15601-15606.

[18] J. Jin, J. Yin, H. Liu, P. Xi, Chin. J. Catal., 2019, 40, 43-51.

[19] S. Dou, X. Li, L. Tao, J. Huo, S. Wang, Chem. Commun., 2016, 52, 9727-9730.

[20] X. Ji, L. Cui, D. Liu, S. Hao, J. Liu, F. Qu, Y. Ma, G. Du, A. M. Asiri, X. Sun, Chem. Commun., 2017, 53, 3070-3073.

[21] J. Yang, X. Wang, B. Li, L. Ma, L. Shi, Y. Xiong, H. Xu, Adv. Funct. Mater., 2017, 27, 1606497.

[22] X. Zhang, X. Zhang, H. Xu, Z. Wu, H. Wang, Y. Liang, Adv. Funct. Mater., 2017, 27, 1606635.

[23] X. Zou, Y. Liu, G. D. Li, Y. Wu, D. P. Liu, W. Li, H. W. Li, D. Wang, Y. Zhang, X. Zou, Adv. Mater, 2017, 29, 1700404.

[24] T. T. H. Nguyen, J. Lee, J. Bae, B. Lim, Chem. Eur. J., 2018, 24, 4724-4728.

[25] K. Xu, P. Chen, X. Li, Y. Tong, H. Ding, X. Wu, W. Chu, Z. Peng, C. Wu, Y. Xie, J. Am. Chem. Soc., 2015, 137, 4119-4125.

[26] X. Lu, W. L. Yim, B. H. R. Suryanto, C. Zhao, J. Am. Chem. Soc., 2015, 137, 2901-2907.

[27] N. Wang, H. Zheng, W. Zhang, R. Cao, Chin. J Catal,, 2018, 39, 228-244.

[28] S. Chen, Y. Zhao, B. Sun, Z. Ao, X. Xie, Y. Wei, G. Wang, ACS Appl. Mater. Interfaces, 2015, 7, 3306-3313.

[29] H. Jin, S. J. Mao, G. Zhan, F. Xu, X. Bao, Y. Wang, J. Mater. Chem. A, 2017, 5, 1078-1084.

[30] L. Wang, C. Lin, D. Huang, F. Zhang, M. Wang, J. Jin, ACS Appl. Mater. Interfaces, 2014, 6, 10172-10180.

[31] J. Li, Q. Zhuang, P. Xu, D. Zhang, L. Wei, D. Yuan, Chin.J Catal., 2018, 39,1403-1410.

[32] Y. Liu, C. Hao, M. Lyu, S. Fan, Q. Liu, W. Zhang, Y. Zhi, C. Wang, X. Chong, S. Wei, J. Am. Chem. Soc., 2014, 136, 15670-15675.

[33] J. Yin, Y. Li, F. Lv, M. Lu, K. Sun, W. Wang, L. Wang, F. Cheng, Y. Li, P. Xi, Adv. Mater., 2017, 29, 1704681.

[34] C. C. Hou, S. Cao, W. F. Fu, Y. Chen, ACS Appl. Mater. Interfaces, 


\section{Graphical Abstract}

Chin. J. Catal., 2019, 40: 1822-1840 doi: S1872-2067(19)63284-5

\section{Electronic structure regulation on layered double hydroxides for oxygen evolution reaction}

Liangliang Huang, Yuqin Zou *, Dawei Chen *, Shuangyin Wang * Hunan University; Qingdao University of Science and Technology; Shenzhen University

A review summarized recent advances in electronic structure regulations, including cationic regulation, anionic regulation, defect engineering, intercalated anions regulating, surface modifications, on LDHs as electrocatalysts for OER. Schematic summarizing the recent advances in electronic structure regulation, including cationic regulation, anionic regulation, defect engineering, intercalated anion regulation, and surface modifications on LDHs as electrocatalysts for OER.

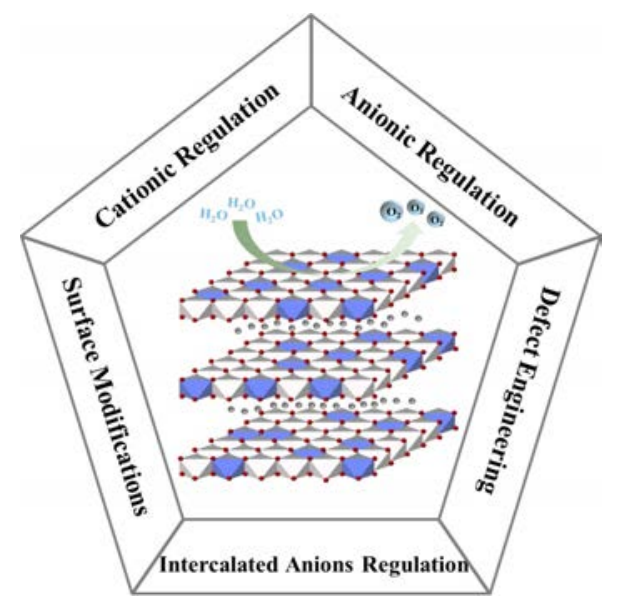

2015, 7, 28412-28419.

[35] Y. Bai, H. Zhang, Y. Feng, L. Fang, Y. Wang, J. Mater. Chem. A, 2016, 4, 9072-9079.

[36] Y. Zhang, B. Ouyang, J. Xu, G. Jia, S. Chen, R. S. Rawat, H. J. Fan, Angew. Chem. Int. Ed., 2016, 55, 8670-8674.

[37] P. Chen, K. Xu, Z. Fang, Y. Tong, J. Wu, X. Lu, X. Peng, H. Ding, C. Wu, Y. Xie, Angew. Chem. Int. Ed., 2015, 54, 14710-14714.

[38] P. Chen, K. Xu, T. Zhou, Y. Tong, J. Wu, H. Cheng, X. Lu, H. Ding, C. $\mathrm{Wu}, \mathrm{Y}$. Xie, Angew. Chem. Int. Ed., 2016, 55, 2488-2492.

[39] L. Yu, H. Zhou, J. Sun, F. Qin, D. Luo, L. Xie, F. Yu, J. Bao, Y. Li, Y. Yu, S. Chen, Z. Ren, Nano Energy, 2017, 41, 327-336.

[40] F. Song, X. Hu, J. Am. Chem. Soc., 2014, 136, 16481-16484.

[41] J. Jiang, A. Zhang, L. Li, L. Ai, J. Power Sources, 2015, 278, 445-451.

[42] L. Feng, A. Li, Y. Li, J. Liu, L. Wang, L. Huang, Y. Wang, X. Ge, Chempluschem, 2017, 82, 483-488.

[43] C. Li, M. Wei, D. G. Evans, X. Duan, Catal. Today, 2015, 247, 163-169.

[44] X. Guo, F. Zhang, D. G. Evans, X. Duan, Chem. Commun., 2010, 46, 5197-5210.

[45] M. Zhao, Q. Zhao, B. Li, H. Xue, H. Pang, C. Chen, Nanoscale, 2017, 9, 15206-15225.

[46] L. Huang, R. Chen, C. Xie, C. Chen, Y. Wang, Y. Zeng, D. Chen, S. Wang, Nanoscale, 2018, 10, 13638-13644.

[47] J. Duan, S. Chen, A. Vasileff, S. Z. Qiao, ACS Nano, 2016, 10, 8738-8745.

[48] H. Liang, F. Meng, M. Cabán-Acevedo, L. Li, A. Forticaux, L. Xiu, Z. Wang, J. Song, Nano Letters, 2015, 15, 1421-1427.

[49] Y. Wang, D. Yan, S. El Hankari, Y. Zou, S. Wang, Adv. Sci., 2018, 5, 1800064

[50] X. Han, C. Yu, J. Yang, C. Zhao, H. Huang, Z. Liu, P. M. Ajayan, J. Qiu, Adv. Mater. Interfaces, 2016, 3, 1500782.

[51] H. Xu, Y. Yuan, Y. Liao, J. Xie, Z. Qu, W. Shangguan, N. Yan, Environ. Sci. Technol., 2017, 51, 10109-10116.

[52] J. Yu, Q. Wang, D. O'Hare, L. Sun, Chem. Soc. Rev., 2017, 46, 5950-5974.

[53] X. Jia, Y. Zhao, G. Chen, L. Shang, R. Shi, X. Kang, G. I. N. Waterhouse, L. Z. Wu, C. H. Tung, T. Zhang, Adv. Energy Mater., 2016, 6, 1502585 .
[54] F. Song, X. Hu, Nat. Commun., 2014, 5, 4477.

[55] W. Zhang, K. Zhou, Small, 2017, 13, 1700806.

[56] J. Huang, J. Chen, T. Yao, J. He, S. Jiang, Z. Sun, Q. Liu, W. Cheng, F. Hu, Y. Jiang, Z. Pan, S. Wei, Angew. Chem. Int. Ed., 2015, 54, 8722-8727.

[57] D. Chen, M. Qiao, Y. R. Lu, L. Hao, D. Liu, C. L. Dong, Y. Li, S. Wang, Angew. Chem. Int. Ed., 2018, 57, 8691-8696.

[58] T. Tang, W. J. Jiang, S. Niu, N. Liu, H. Luo, Y. Y. Chen, S. F. Jin, F. Gao, L. J. Wan, J. S. Hu, J. Am. Chem. Soc., 2017, 139, 8320-8328.

[59] C. Hu, L. Zhang, Z. J. Zhao, A. Li, X. Chang, J. Gong, Adv. Mater., 2018, 30, 1705538.

[60] L. Fang, W. Li, Y. Guan, Y. Feng, H. Zhang, S. Wang, Y. Wang, Adv. Funct. Mater., 2017, 27, 1701008.

[61] L. Xu, Q. Jiang, Z. Xiao, X. Li, J. Huo, S. Wang, L. Dai, Angew. Chem. Int. Ed., 2016, 55, 5277-5281.

[62] X. Xiong, Z. Cai, D. Zhou, G. Zhang, Q. Zhang, Y. Jia, X. Duan, Q. Xie, S. Lai, T. Xie, Y. Li, X. Sun, X. Duan, Sci. China Mater., 2018, 61, 939-947.

[63] Y. Wang, M. Qiao, Y. Li, S. Wang, Small, 2018, 14, 1800136.

[64] J. S. Kim, B. Kim, H. Kim, K. Kang, Adv. Energy Mater., 2018, 8, 1702774.

[65] W. T. Hong, M. Risch, K. A. Stoerzinger, A. Grimaud, S. Jin, S. H. Yang, Energy Environ. Sci., 2015, 8, 1404-1427.

[66] F. Lu, M. Zhou, Y. Zhou, X. Zeng, Small, 2017, 13, 1701931.

[67] P. Liao, J. A. Keith, E. A. Carter, J. Am. Chem. Soc., 2012, 134, 13296-13309.

[68] B. Zhang, X. Zheng, O. Voznyy, R. Comin, M. Bajdich, M. Garcã-A-Melchor, L. Han, J. Xu, M. Liu, L. Zheng, Science, 2016, 352, 333-337.

[69] O. Diaz-Morales, I. Ledezma-Yanez, M. T. M. Koper, F. Calle-Vallejo, ACS Catal., 2015, 5, 5380-5387.

[70] D. Friebel, M. W. Louie, M. Bajdich, K. E. Sanwald, Y. Cai, A. M. Wise, M. J. Cheng, D. Sokaras, T. C. Weng, R. Alonso-Mori, R. C. Davis, J. R. Bargar, J. K. Noerskov, A. Nilsson, A. T. Bell, J. Am. Chem. Soc., 2015, 137, 1305-1313.

[71] H. Xu, B. Wang, C. Shan, P. Xi, W. Liu, Y. Tang, ACS Appl. Mater. Interfaces, 2018, 10, 6336-6345.

[72] J. K. Nørskov, T. Bligaard, J. Rossmeisl, C. H. Christensen, Nat. 
Chem., 2009, 1, 37-46.

[73] B. Hammer, J. K. Nørskov, Adv. Catal., 2000, 45, 71-129.

[74] K. Liang, Y. Yan, L. Guo, K. Marcus, Z. Li, L. Zhou, Y. Li, R. Ye, N. Orlovskaya, Y. H. Sohn, ACS Energy Lett., 2017, 2, 1315-1320.

[75] C. Xiao, X. Lu, C. Zhao, Chem. Commun., 2014, 50, 10122-10125.

[76] C. Tang, R. Zhang, W. Lu, L. He, X. Jiang, A. M. Asiri, X. Sun, Adv. Mater., 2017, 29, 1602441.

[77] H. F. Wang, C. Tang, B. Q. Li, Q. Zhang, Inorg. Chem. Front., 2018, $5,521-534$

[78] X. Long, S. Xiao, Z. Wang, X. Zheng, S. Yang, Chem. Commun., 2015, 51, 1120-1123.

[79] A. C. Thenuwara, N. H. Attanayake, Q. Yan, D. R. Strongin, J. Yu, J. P. Perdew, E. J. Elzinga, J. Phys. Chem. B, 2018, 122, 847-854.

[80] L. J. Foruzin, Z. Rezvani, Y. H. Shishavan, B. Habibi, Int. J. Hydrogen Energy, 2018, 43, 150-160.

[81] H. Liu, Y. Wang, X. Lu, Y. Hu, G. Zhu, R. Chen, L. Ma, H. Zhu, Z. Tie, J. Liu, Z. Jin, Nano Energy, 2017, 35, 350-357.

[82] Q. Q. Chen, C. C. Hou, C. J. Wang, X. Yang, R. Shi, Y. Chen, Chem. Commun., 2018, 54, 6400-6403.

[83] Y. Yang, L. Dang, M. J. Shearer, H. Sheng, W. Li, J. Chen, P. Xiao, Y. Zhang, R. J. Hamers, S. Jin, Adv. Energy Mater., 2018, 8, 1703189.

[84] L. Qian, Z. Lu, T. Xu, X. Wu, Y. Tian, Y. Li, Z. Huo, X. Sun, X. Duan, Adv. Energy Mater., 2015, 5, 1500245.

[85] Q. Yang, T. Li, Z. Lu, X. Sun, J. Liu, Nanoscale, 2014, 6, 11789-11794.

[86] T. Wang, W. Xu, H. Wang, Electrochim. Acta, 2017, 257, 118-127.

[87] P. Li, X. Duan, Y. Kuang, Y. Li, G. Zhang, W. Liu, X. Sun, Adv. Energy Mater., 2018, 8, 1703341.

[88] K. N. Dinh, P. Zheng, Z. Dai, Y. Zhang, R. Dangol, Y. Zheng, B. Li, Y. Zong, Q. Yan, Small, 2018, 14, 1703257.

[89] Z. Lu, L. Qian, Y. Tian, Y. Li, X. Sun, X. Duan, Chem. Commun., 2016, 52, 908-911.

[90] S. Dey, B. Mondal, A. Dey, Phys. Chem. Chem. Phys., 2014, 16, 12221-12227.

[91] Z. Xiao, Y. Wang, Y. C. Huang, Z. Wei, C. L. Dong, J. Ma, S. Shen, Y. Li, S. Wang, Energy Environ. Sci., 2017, 10, 2563-2569.

[92] A. Grimaud, W. T. Hong, Y. Shao-Horn, J. M. Tarascon, Nat. Mater., 2016, 15, 121-126.

[93] B. Q. Li, S. Y. Zhang, C. Tang, X. Cui, Q. Zhang, Small, 2017, 13, 1700610

[94] J. Hao, W. Yang, Z. Peng, C. Zhang, Z. Huang, W. Shi, ACS Catal., 2017, 7, 4214-4220.

[95] B. Ananthoju, J. Mohapatra, M. K. Jangid, D. Bahadur, N. V. Medhekar, M. Aslam, Sci. Rep., 2016, 6, 35369.

[96] H. F. Wang, C. Tang, B. Wang, B. Q. Li, Q. Zhang, Adv. Mater., 2017, $29,1702327$.

[97] L. Qian, W. Chen, M. Liu, Q. Jia, D. Xiao, ChemElectroChem, 2016, 3, 950-958.

[98] L. M. Cao, J. W. Wang, D. C. Zhong, T. B. Lu, J. Mater. Chem. A, 2018, 6, 3224-3230.

[99] Y. Wang, C. Xie, Z. Zhang, D. Liu, R. Chen, S. Wang, Adv. Funct. Mater., 2018, 28, 1703363.

[100] L. Cai, J. He, Q. Liu, T. Yao, L. Chen, W. Yan, F. Hu, Y. Jiang, Y. Zhao, T. Hu, Z. Sun, S. Wei, J. Am. Chem. Soc., 2015, 137, 2622-2627.

[101] J. Chen, Y. Han, X. Kong, X. Deng, H. J. Park, Y. Guo, S. Jin, Z. Qi, Z. Lee, Z. Qiao, R. S. Ruoff, H. Ji, Angew. Chem. Int. Ed., 2016, 55, 13822-13827.

[102] Z. Cai, Y. Bi, E. Hu, W. Liu, N. Dwarica, Y. Tian, X. Li, Y. Kuang, Y. Li, X. Q. Yang, H. Wang, X. Sun, Adv. Energy Mater., 2018, 8, 1701694.

[103] Y. Sun, S. Gao, F. Lei, Y. Xie, Chem. Soc. Rev., 2015, 44, 623-636.

[104] D. Yan, Y. Li, J. Huo, R. Chen, L. Dai, S. Wang, Adv. Mater., 2017,
$29,1606459$.

[105] M. Guan, C. Xiao, J. Zhang, S. Fan, R. An, Q. Cheng, J. Xie, M. Zhou, B. Ye, Y. Xie, J. Am. Chem. Soc., 2013, 135, 10411-10417.

[106] S. Polarz, J. Strunk, V. Ischenko, M. W. E. van den Berg, O. Hinrichsen, M. Muhler, M. Driess, Angew. Chem. Int. Ed., 2006, 45, 2965-2969.

[107] Y. Wang, Y. Zhang, Z. Liu, C. Xie, S. Feng, D. Liu, M. Shao, S. Wang, Angew. Chem. Int. Ed., 2017, 56, 5867-5871.

[108] S. Jin, K. J. May, H. A. Gasteiger, J. B. Goodenough, S. H. Yang, Science, 2011, 334, 1383-1385.

[109] T. Ling, D. Y. Yan, Y. Jiao, H. Wang, Y. Zheng, X. Zheng, J. Mao, X. W. Du, Z. Hu, M. Jaroniec, S. Z. Qiao, Nat. Commun., 2016, 7, 12876.

[110] Y. Guo, Y. Tong, P. Chen, K. Xu, J. Zhao, Y. Lin, W. Chu, Z. Peng, C. Wu, Y. Xie, Adv. Mater., 2015, 27, 5989-5994.

[111] Y. Tong, P. Chen, M. Zhang, T. Zhou, L. Zhang, W. Chu, C. Wu, Y. Xie, ACS Catal., 2017, 8, 1-7.

[112] G. Huang, Z. Xiao, R. Chen, S. Wang, ACS Sustain. Chem. Eng., 2018, 6, 15954-15969.

[113] Z. Cai, Y. Bi, E. Hu, W. Liu, N. Dwarica, Y. Tian, X. Li, Y. Kuang, Y. Li, X. Q. Yang, H. Wang, X. Sun, Adv. Energy Mater., 2018, 8, 1701694

[114] M. Kuang, P. Han, L. Huang, N. Cao, L. Qian, G. Zheng, Adv. Funct. Mater., 2018, DOI: 10.1002/adfm.201804886.

[115] P. F. Liu, S. Yang, B. Zhang, H. G. Yang, ACS Appl. Mater. Interfaces, 2016, 8, 34474-34481.

[116] T. Chinnusamy, V. Rodionov, F. E. Kühn, O. Reiser, Nat. Chem., 2011, 3, 79-84.

[117] Q. Xie, Z. Cai, P. Li, D. Zhou, Y. Bi, X. Xiong, E. Hu, Y. Li, Y. Kuang, X. Sun, Nano Res., 2018, 11, 4524-4534.

[118] R. Liu, Y. Wang, D. Liu, Y. Zou, S. Wang, Adv. Mater., 2017, 29, 1701546.

[119] P. Zhou, Y. Wang, C. Xie, C. Chen, H. Liu, R. Chen, J. Huo, S. Wang, Chem. Commun., 2017, 53, 11778-11781.

[120] R. Gao, D. Yan, Nano Res., 2018, 11, 1883-1894.

[121] L. Wei, H. E. Karahan, S. Zhai, H. Liu, X. Chen, Z. Zhou, Y. Lei, Z. Liu, Y. Chen, Adv. Mater., 2017, 29, 1701410.

[122] C. Hu, L. Zhang, Z. J. Zhao, J. Luo, J. Shi, Z. Huang, J. Gong, Adv. Mater., 2017, 29, 1701820.

[123] J. Xie, H. Qu, F. Lei, X. Peng, W. Liu, L. Gao, P. Hao, G. Cui, B. Tang, J. Mater. Chem. A, 2018, 6, 16121-16129.

[124] J. Nai, H. Yin, T. You, L. Zheng, J. Zhang, P. Wang, Z. Jin, Y. Tian, J. Liu, Z. Tang, Adv. Energy Mater., 2015, 5, 1401880.

[125] L. Xu, Z. Wang, X. Chen, Z. Qu, F. Li, W. Yang, Electrochim. Acta, 2018, 260, 898-904.

[126] K. Yan, T. Lafleur, J. Chai, C. Jarvis, Electrochem. Commun., 2016, 62, 24-28.

[127] Q. Kang, L. Vernisse, R. C. Remsing, A. C. Thenuwara, S. L. Shumlas, I. G. McKendry, M. L. Klein, E. Borguet, M. J. Zdilla, D. R. Strongin, J. Am. Chem. Soc., 2017, 139, 1863-1870.

[128] X. Li, X. Hao, Z. Wang, A. Abudula, G. Guan, J. Power Sources, 2017, 347, 193-200.

[129] Y. Xu, Y. Hao, G. Zhang, Z. Lu, S. Han, Y. Li, X. Sun, RSC Adv., 2015, 5, 55131-55135.

[130] L. Z. Li, F. Han, C. Li, X. Jiao, D. Chen, Chem. Asian J., 2018, 13, 1129-2237.

[131] M. Luo, Z. Cai, C. Wang, Y. Bi, L. Qian, Y. Hao, L. Li, Y. Kuang, Y. Li, X. Lei, Z. Huo, W. Liu, H. Wang, X. Sun, X. Duan, Nano Res., 2017, 10, 1732-1739.

[132] L. Su, H. Du, C. Tang, K. Nan, J. Wu, C. M. Li, J. Colloid Interfaces Sci., 2018, 528, 36-44.

[133] N. Han, F. Zhao, Y. Li, J. Mater. Chem. A, 2015, 3, 16348-16353. 
[134] K. Nejati, A. R. Akbari, S. Davari, K. Asadpour-Zeynali, Z. Rezvani, New J. Chem., 2018, 42, 2889-2895.

[135] B. M. Hunter, W. Hieringer, J. R. Winkler, H. B. Gray, A. M. Müller, Energy Environ. Sci., 2016, 9, 1734-1743.

[136] L. Dang, H. Liang, J. Zhuo, B. K. Lamb, H. Sheng, Y. Yang, S. Jin, Chem. Mater., 2018, 30, 4321-4330.

[137] Y. Wang, K. Jiang, W. Wei, W. B. Cai, G. Zheng, H. Zhang, J. Wang, X. Sun, T. Zhou, Z. Yang, Adv. Sci., 2015, 2, 1500003.

[138] M. Flytzani-Stephanopoulos, Acc. Chem. Res., 2014, 47, 783-792.

[139] P. Liu, Y. Zhao, R. Qin, S. Mo, G. Chen, L. Gu, D. M. Chevrier, P.
Zhang, Q. Guo, D. Zang, B. Wu, G. Fu, N. Zheng, Science, 2016, 352, 797-800.

[140] S. Anantharaj, K. Karthick, M. Venkatesh, T. V. S. V. Simha, A. S. Salunke, L. Ma, H. Liang, S. Kundu, Nano Energy, 2017, 39, 30-43.

[141] M. Taei, E. Havakeshian, F. Hasheminasab, RSC Adv., 2017, 7, 47049-47055.

[142] W. Zhu, L. Liu, Z. Yue, W. Zhang, X. Yue, J. Wang, S. Yu, L. Wang, J. Wang, ACS Appl. Mater. Interfaces, 2017, 9, 19807-19814.

[143] J. Zhang, J. Liu, L. Xi, Y. Yu, N. Chen, S. Sun, W. Wang, K. M. Lange, B. Zhang, J. Am. Chem. Soc., 2018, 140, 3876-3879.

\title{
调控层状双金属氢氧化物电子结构促进氧析出反应
}

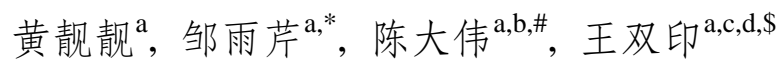 \\ a 湖南大学化学化工学院, 湖南省碳材料与电化学能源实验室, 化学生物传感与计量学国家重点实验室, 湖南长沙 410082

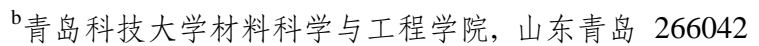 \\ c 深圳大学光电子器件与系统教育部重点实验室, 广东深圳 518060

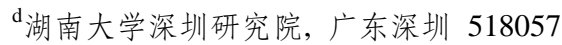

摘要: 氢气具有能量密度高、无毒、燃烧产物无环境污染等优点, 是一种极具应用前景的可再生能源. 目前制氢技术主要 包括天然气重整制氢、光解水制氢及电解水制氢, 其中天然气重整制氢存在纯度低、成本高的缺点, 而光解水制氢技术尚 不成熟. 电解水制氢纯度高、成本低, 已成为一种比较常用且成熟的制氢方法. 电解水过程是指在电解池中利用电能分解 水分子并释放出氢气和氧气的电化学过程, 它包含两个半反应, 即阳极析氧反应(OER)和阴极析氢反应(HER). 在室温下驱 动析氢反应与析氧反应的理论电位分别为 0 与 $1.23 \mathrm{~V}$. 但是, 在实际电解过程中需要额外的电位(过电位)去激活和克服原始 反应能垒, 因此, 尽可能的降低电解水的过电位是氢能广泛应用的必要条件. 过渡金属化合物, 特别是层状双金属氢氧化 物(LDHs), 由于其独特的二维层状结构和组成元素可灵活调变等特性, 被认为是最具发展前景的电催化剂之一. 但LDHs 较差的电子导电性和较厚的板层结构极大的限制了其作为氧析出电催化剂的大规模应用. 本文总结了LDHs作为OER电催 化剂的研究进展, 重点介绍了不同阳离子、不同阴离子、缺陷工程、各类插层阴离子和表面改性等改变对材料表面电子结 构的影响机制.

本文首先介绍了电解水析氧反应在不同电解液中的反应机理, 讨论了析氧反应在动力学和热力学过程的主要障碍. 通过对大量文献的归纳, 综述了近年来通过调控LDHs的电子结构增加其活性位点数目、增强活性位点的本征活性, 进而提 高其OER催化性能的研究成果和最新进展, 重点探讨了阳离子调控、阴离子调控、缺陷工程、插层阴离子调控和表面改性 等调控方式对LDHs电催化剂OER性能的影响, 总结了各种电子结构调控及其对电催化性能的影响. 通过分析不同价态阳 离子、阴离子对催化活性位点的电子结构影响, 不同层间插层阴离子对催化剂层间距的影响, 不同类型缺陷带来的微观结 构和表层电子结构变化及表面改性带来的表层电子状态, 亲疏水性的区别等实验现象, 总结了层状过渡金属氢氧化物OER 性能提升的策略. 此外, 本文还做了在LDHs的催化性能调控方面的挑战和展望, 对未来开发和设计高效的OER电催化剂提 供了崭新的思路.

关键词: 氧析出反应; 层状双金属氢氧化物; 阳离子/阴离子调控; 缺陷工程; 电催化剂; 电子; 掺杂

收稿日期: 2019-01-05. 接受日期: 2019-02-13. 出版日期: 2019-12-05.

*通讯联系人. 电子邮箱: yuqin_zou@hnu.edu.cn

\#通讯联系人. 电子邮箱: daweichen@qust.edu.cn

\$通讯联系人. 电子邮箱: shuangyinwang@hnu.edu.cn

基金来源：国家自然科学基金(51402100, 21573066, 21825201).

本文的电子版全文由Elsevier出版社在ScienceDirect上出版(http://www.sciencedirect.com/science/journal/18722067). 